Universidade de São Paulo Faculdade de Medicina de Ribeirão Preto
2019

ANÁLISE DA SENSIBILIDADE DISCRIMINATIVA DE DOIS PONTOS E JULGAMENTO DE LATERALIDADE EM INDIVÍDUOS COM DOR CRÔNICA UNILATERAL NÃO TRAUMÁTICA NO OMBRO - UM ESTUDO TRANSVERSAL

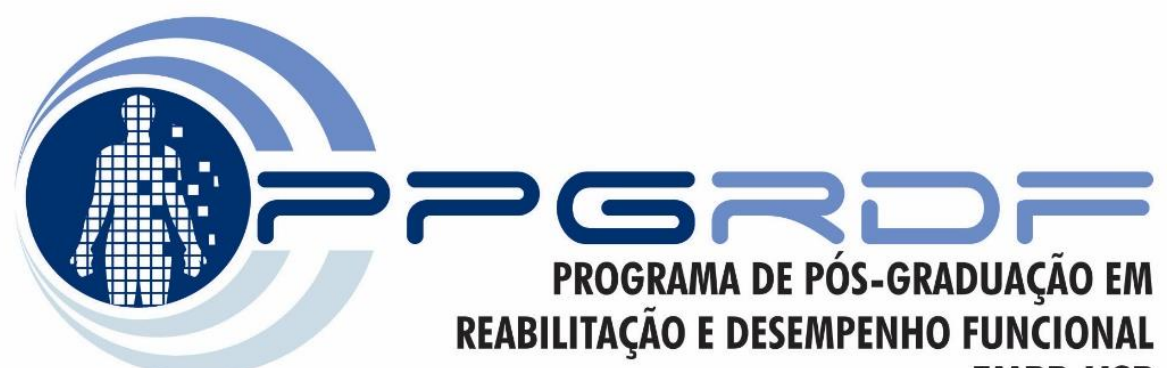

FMRP-USP

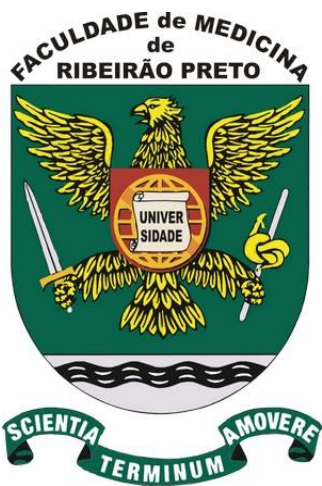

Marília Caseiro

Dissertação 


\title{
Análise da sensibilidade discriminativa de dois pontos e julgamento de lateralidade em indivíduos com dor crônica unilateral não traumática no ombro - um estudo transversal
}

\begin{abstract}
Dissertação apresentada para o Programa de Pós-Graduação em Reabilitação e Desempenho Funcional da Faculdade de Medicina de Ribeirão Preto FMRP/USP para obtenção do título de Mestre em Ciências.

Área de concentração: Fisioterapia

Orientadora: Profa Dra. Anamaria Siriani de Oliveira Colaborador: Prof. Dr. Felipe José Jandre dos Reis
\end{abstract}


Autorizo a reprodução e divulgação total ou parcial deste trabalho, por qualquer meio convencional ou eletrônico, para fins de estudo e pesquisa, desde que citada a fonte.

Caseiro, Marília

Análise da sensibilidade discriminativa de dois pontos e julgamento de lateralidade em indivíduos com dor crônica unilateral não traumática no ombro - um estudo transversal. Ribeirão Preto, 2019.

56 p.: il.; $30 \mathrm{~cm}$

Dissertação de Mestrado, apresentada à Faculdade de Medicina de Ribeirão Preto/USP. Área de concentração: Fisioterapia.

Orientadora: Siriani de Oliveira, Anamaria.

1. Ombro. 2. Dor Crônica 3. Reorganização Cortical. 4. Teste de Discriminação de Dois Pontos 


\author{
Universidade de São Paulo \\ Faculdade de Medicina de Ribeirão Preto
}

MARÍLIA CASEIRO

Análise da sensibilidade discriminativa de dois pontos e julgamento de lateralidade em indivíduos com dor crônica unilateral não traumática no ombro - um estudo transversal

Ribeirão Preto 
Marília Caseiro

Análise da sensibilidade discriminativa de dois pontos e julgamento de lateralidade em indivíduos com dor crônica unilateral não traumática no ombro - um estudo transversal

Dissertação apresentada ao Programa de Pós-Graduação em Reabilitação e Desempenho Funcional da Faculdade de Medicina de Ribeirão Preto da Universidade de São Paulo para obtenção do título de Mestre.

Aprovado em:

Banca examinadora

Prof. Dr. Instituição:

Julgamento: Assinatura:

Prof. Dr Instituição:

Julgamento: Assinatura:

Prof. Dr. Instituição:

Julgamento: Assinatura: 


\section{DEDICATÓRIA}

Aos meus amados pais, Edson e Lígia, as minhas queridas irmãs Juliana e Gabriela, e ao meu companheiro de vida Samuel por sempre me lembrarem da minha essência e serem meu suporte. 


\section{AGRADECIMENTOS}

Agradeço imensamente a Deus, por ter me permitido viver mais essa etapa da minha vida, com saúde e força para conquistar esse sonho.

A meus pais, agradeço a todas as palavras de incentivo para cada desafio enfrentado. Mãe, você sempre teve as palavras certas para me consolar e acolher, obrigada por todo o cuidado e carinho. Pai, obrigada por todo o suporte e direcionamento, dividir com você os passos dessa jornada foi essencial.

A minha irmã Gabriela e meu cunhado Rafael e minha irmã Juliana e meu cunhado Mário. Neste processo do meu mestrado vocês se tornaram mães então nós três tivemos a realização de alguns sonhos juntas. Agradeço a parceria, carinho e ajuda no decorrer da conquista deste sonho.

Ao meu marido, agradeço imensamente ao companheirismo e amor construídos nesta fase. O mestrado foi uma etapa que vivenciamos ao mesmo tempo nas nossas vidas, e ainda decidimos neste período, determinar nossa união através do casamento. Foi uma decisão muito importante, mas que só trouxe alegria. Mais um sonho conquistado.

As minhas amigas Sulamita, Marcela e Camila agradeço as risadas, conselhos, e momentos de escuta que trazem paz e aconchego para qualquer momento desafiador que pode ser enfrentado no decorrer desta etapa. Vocês me fizeram sempre relembrar de onde eu vim.

Aos meus colegas de laboratório, agradeço demais a parceria de vocês. Só posso dizer que vocês são a base de tudo. Se consegui chegar ao fim, foi porque vocês me 
direcionaram e me ensinaram por onde eu deveria começar. Vocês ficarão eternamente em meu coração.

A minha colega de pesquisa Amanda Matias Barbosa pela companhia, amizade, ajuda, paciência e bondade. Entrei para realizar um projeto sozinha e sai realizando coletas, escrita, análise, participação em evento com a sua parceria e apoio. Você foi essencial para que eu conseguisse chegar até o fim. Obrigada pela leveza e por todas as risadas. Tudo valeu a pena.

Ao nosso colaborador e coorientador de pesquisa Prof. Dr. Felipe Jose Jandre dos Reis do Instituto Federal do Rio de Janeiro - IFRJ pela imensa ajuda e orientação na nossa pesquisa. O início da parceria com o professor começa com esse projeto e me sinto imensamente honrada em fazer parte disso. Não tenho palavras para agradecer a influência positiva da postura e ética profissional que levo como aprendizado para minha vida. As colaborações nessa pesquisa foram incrivelmente relevantes e posso afirmar que levo todas elas como aprendizado, sendo possível reproduzir os ensinamentos na minha prática atual, como docente, ou pelo menos tentar. De qualquer maneira, agradeço a inspiração para seguir no meu caminho. Muito obrigada.

A minha orientadora Prof. Dra. Anamaria Siriani pela acolhida desde agosto de 2015, quando eu ainda era uma aluna de graduação. Cheguei com muitos sonhos, com pouquíssima experiência, mas com muita vontade de estar por perto de você e do laboratório. Desde o começo, não sabia dimensionar o quanto me sentia grata por tudo o que aprendia e por todas as oportunidades que me dava. E aos poucos você foi me ensinando que podia seguir sozinha e confiar em mim. Mas eu pude aprender isso pois você foi meu maior exemplo. Ao te observar e ouvir, eu aprendi muito e agradeço a cada conselho, correção e ensinamento. Você sem dúvidas é a melhor professora que já tive, sua organização e didática fizeram parte da minha construção como docente. Diversos desafios enfrentados na prática docente me peguei pensando de que maneira você resolveria aquela situação, pois você é um grande exemplo para mim. Obrigada por me acolher. Obrigada por me mostrar o caminho. Obrigada por me orientar. 


\section{RESUMO}

CASEIRO, M. Análise da sensibilidade discriminativa de dois pontos e julgamento de lateralidade em indivíduos com dor crônica unilateral não traumática no ombro - um estudo transversal. 2019. 56 p. Dissertação (Mestrado). Faculdade de Medicina de Ribeirão Preto - Universidade de São Paulo, Ribeirão Preto, 2019.

Introdução: A dor no ombro é uma das queixas musculoesqueléticas mais frequentes levando ao prejuízo da incapacidade funcional. Independentemente da opção de tratamento, um terço dos pacientes não apresentam resultados satisfatórios com a intervenção escolhida, e desta maneira, continuam a apresentar sintomas como dor e incapacidade. A literatura atual destaca que a dor, especialmente a crônica, provoca alterações funcionais e estruturais em diversas regiões do cérebro que poderiam contribuir ou mesmo justificar a manutenção do estado doloroso. Objetivo: Comparar a discriminação de dois pontos entre lado acometido e não acometido e o julgamento de lateralidade dos segmentos ombro e pé em indivíduos com dor crônica unilateral não traumática no ombro; Avaliar a confiabilidade intra-examinador do Teste de Discriminação de Dois Pontos (TDDP) em indivíduos com dor crônica unilateral no ombro; Analisar a relação entre as variáveis do TDDP e Julgamento de Lateralidade (JL) com área corporal, escore da escala de catastrofização relacionada a dor (PCS) e escore da escala de afetos positivos e negativos (PANAS). Métodos: 52 indivíduos de ambos os sexos, a partir dos 30 anos, com dor no ombro unilateral não traumática passaram por uma avaliação contendo perguntas iniciais para caracterização do indivíduo além dos questionários de incapacidade relacionada a dor no ombro (SPADI), PANAS e PCS. Após os questionários, foi realizado a primeira aplicação do TDDP seguido pela mensuração da área dolorosa; após, o indivíduo realizou o JL e a segunda medida do TDDP. Resultados: Não houve diferença significativa entre os lados no TDDP e entre os segmentos no JL. A confiabilidade intra-examinador se mostrou boa a excelente no lado acometido ( $\mathrm{ICC}=0,77-0,86)$ e moderada no lado não acometido $(\mathrm{ICC}=0,40-0,50)$. O escore PCS foi capaz de predizer a incapacidade dos indivíduos $(\mathrm{p} \leq 0,05)$ avaliada pelo SPADI.

Palavras Chave: ombro, dor crônica, reorganização cortical, teste de discriminação de dois pontos. 


\begin{abstract}
CASEIRO, M. Two point discrimination test and judgment of laterality analysis $i$ chronic unilateral non traumatic shoulder pain - a cross-sectional study $2019.56 \mathrm{p}$. Dissertation (Master degree). Ribeirão Preto Medical School - University of São Paulo, Ribeirão Preto, 2019.
\end{abstract}

Background: Shoulder pain is one of the most frequent musculoskeletal complaints leading to impairment of functional disability. Regardless of the treatment option, one third of the patients do not present satisfactory results with the intervention chosen, and in this way, they continue to present symptoms such as pain and disability. The current literature highlights that pain, especially chronic pain, causes functional and structural changes in various regions of the brain that could contribute or even justify maintaining the painful state. Aim: Compare the two-point discrimination between the affected and non-affected side and the laterality judgment of the shoulder and foot segments in individuals with unilateral chronic non-traumatic shoulder pain; To assess the intraexaminer reliability of the Two-Point Discrimination Test (TDDP) in individuals with unilateral chronic shoulder pain; To analyze the relationship between TDDP and Laterality Judgment (JL) with body area, pain-related catastrophic scale score (PCS) and positive and negative affect scale score (PANAS). Methods: Fifty-two individuals of both sexes, from the age of 30, with unilateral non-traumatic shoulder pain underwent an assessment containing initial questions to characterize the individual in addition to the shoulder pain-related disability (SPADI) questionnaires, PANAS and PCS. After the questionnaires, the first application of TDDP was carried out followed by the measurement of the pain area; after, the individual performed JL and the second TDDP measure. Results: There was no significant difference between the sides in the TDDP and between the segments in the JL. Intra-examiner reliability was good to excellent on the affected side (ICC $=0.77-0.86$ ) and moderate on the non-affected side (ICC $=0.40-0.50)$. The PCS score was able to predict individuals' disability $(\mathrm{p} \leq 0.05)$ as assessed by SPADI.

Keywords: shouder, chronic pain, cortical reorganization, two point discrimination test. 


\section{LISTA DE ILUSTRAÇÕES}

Figura 1. Pontos de aplicação do TDDP; Região anterior e superior (Ponto 1), Inserção distal do m. Deltóide (Ponto 2). Fonte: Laboratório de Análise da Postura e do Movimento Humano - LAPOMH. 26

Figura 2. Aplicação do método staircase adaptado. Início na distância de $20 \mathrm{~mm}$. Os picos representam os pontos de virada onde o participante relatou sentir um ou dois pontos. Totalizando 2 subidas e 2 descidas. $\mathrm{O}$ mesmo procedimento foi realizado para o ponto 1 e 2 no ombro acometido e não acometido.

Figura 3: Fluxograma de participantes incluídos e avaliados na pesquisa. 30 


\section{LISTA DE TABELAS}

Tabela 1. Caracterização da amostra e escores dos questionários de incapacidade,

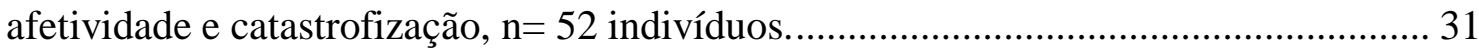

Tabela 2. Média da distância $(\mathrm{mm})$ e comparação entre ombro acometido e não acometido no TDDP.

Tabela 3. Análise da confiabilidade intra-examinador no TDDP

Tabela 4. Média de tempo e acertos no julgamento de lateralidade e comparação entre os segmentos ombro e pé, $\mathrm{n}=52$ indivíduos.

Tabela 5. Modelo de regressão linear múltipla com área corporal como variável dependente, $\mathrm{n}=52$ indivíduos.

Tabela 6. Modelo de regressão linear múltipla com incapacidade como variável dependente, $\mathrm{n}=52$ indivíduos.

Tabela 7. Modelo de regressão linear simples com incapacidade como variável dependente, $\mathrm{n}=52$ indivíduos.

Tabela 8. Modelo de regressão linear simples com área corporal como variável dependente, $\mathrm{n}=52$ indivíduos. 


\section{LISTA DE ABREVIATURAS E SIGLAS}

AN - Afetos Negativos

AP - Afetos Positivos

ARCO - Ambulatório de Reabilitação do Complexo do Ombro

CA - Córtex Cingulado Anterior

CAAE - Certificado de Apresentação para Apreciação Ética

CSE - Centro Saúde Escola

DMN - Default Mode Network

DP - Desvio Padrão

END - Escala Númérica de Dor

EPM - Erro Padrão da Medida

FMRP - Faculdade de Medicina de Ribeirão Preto

I - Córtex Insular

IC - Intervalo de Confiança

ICC - Coeficiente de Correlação Intraclasse

JL - Julgamento de Lateralidade

M1 - Córtex Motor Primário

MMD - Mínima Mudança Detectável

PANAS - Positive and Negative affective Scale

PCS - Pain Catastrophizing Scale

$\mathrm{PF}$ - Córtex pré-frontal

RC - Reorganização Cortical

SAS - Statistical Analysis System

S1 - Córtex Somatossensorial Primário

S2 - Córtex Somatossensorial Secundário

SMS - Secretaria Municipal de Saúde

SPADI - Índice de Incapacidade Relacionado a Dor no Ombro

SPSS - Statistical Package for the Social Sciences

T- Tálamo

TCLE - Termo de Consentimento Livre e Esclarecido 
TDDP - Teste de Discriminação de Dois Pontos

USP - Universidade de São Paulo 


\section{SUMÁRIO}

RESUMO

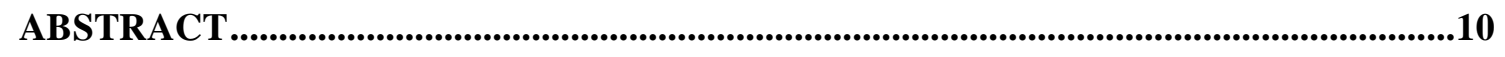

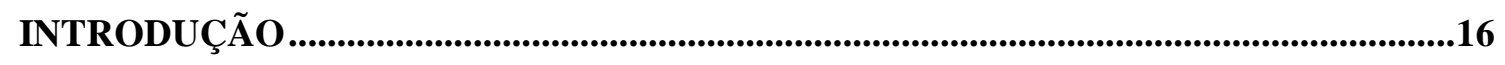

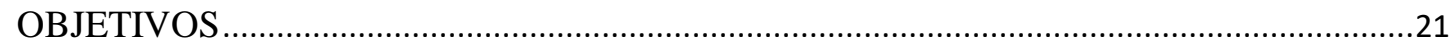

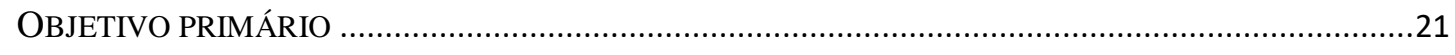

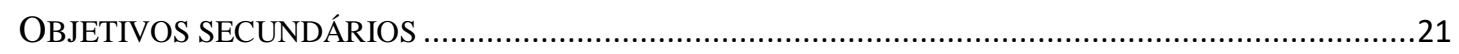

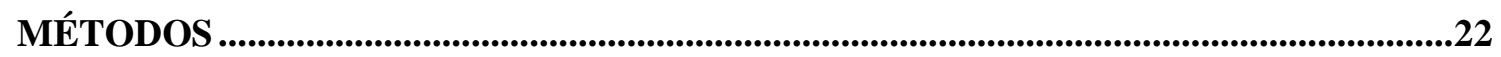

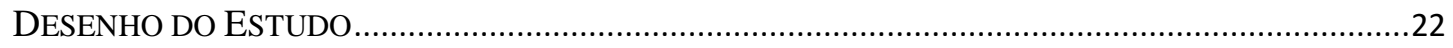

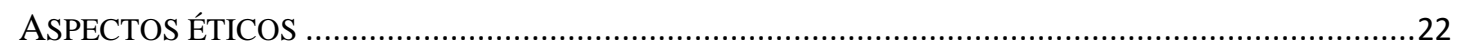

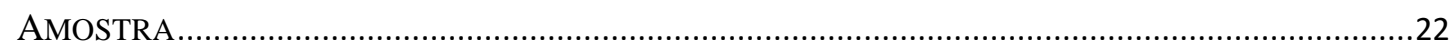

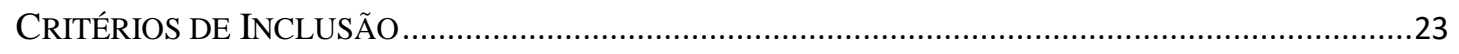

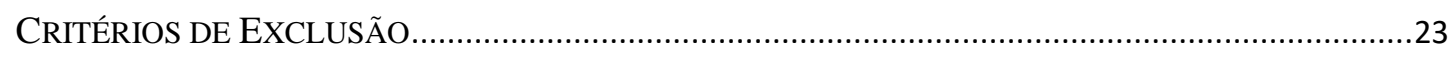

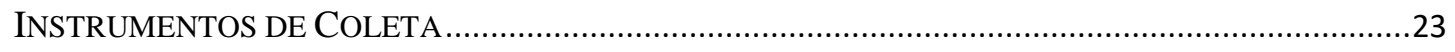

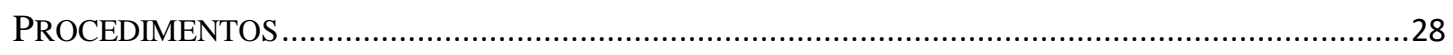

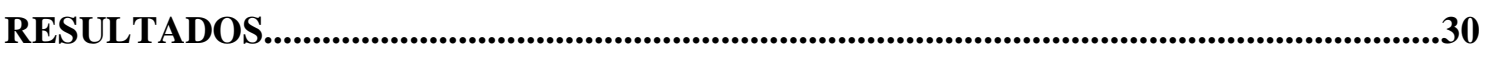

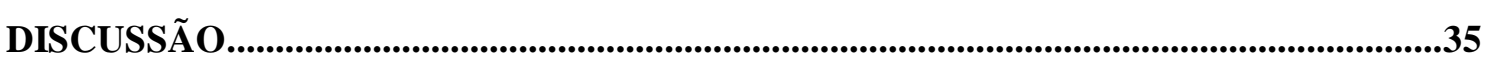

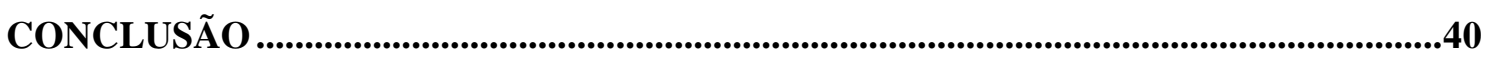

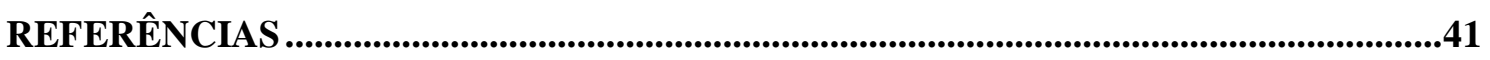

APÊNDICE A - FICHA DE AVALIAÇÃO..........................................................47

APÊNDICE B - TERMO DE CONSENTIMENTO LIVRE E ESCLARECIDO................49

ANEXO A - PARECER COMITÊ DE ÉTICA .......................................................51

ANEXO C - POSITIVE AND NEGATIVE AFFECTIVE SCALE - PANAS ....................55

ANEXO D - ESCALA DE PENSAMENTOS CATASTRÓFICOS - PCS...........................56 


\section{INTRODUÇÃO}

A dor no ombro é umas das queixas musculoesqueléticas mais frequentes apresentando uma alta incidência e gerando custos elevados para o seu gerenciamento (KUIJPERS et al., 2006). Entre as condições dolorosas do ombro as tendinopatias do manguito rotador representam de 35\% a 50\% dos diagnósticos clínicos (NGOMO et al, 2015). O quadro clínico das tendinopatias do manguito rotador comumente inclui dor, incapacidade funcional, prejuízo à capacidade física no trabalho e alterações do sono (BORSTAD, WOESTE, 2015). A longo prazo, os estudos sugerem que a reabilitação conservadora fornece resultados comparáveis à cirurgia (NGOMO et al, 2015).

Independentemente da opção de tratamento, um terço dos pacientes não apresentam resultados satisfatórios com a intervenção escolhida, e desta maneira, continuam a apresentar sintomas como dor e incapacidade (SEITZ et al 2011). Em muitos casos, as dores no ombro se tornam crônica e passam a ser um grande desafio. A literatura atual destaca que a dor, especialmente a crônica, provoca alterações funcionais e estruturais em diversas regiões do cérebro que poderiam contribuir ou mesmo justificar a manutenção do estado doloroso (BALIKI et al, 2011).

O avanço das técnicas de neuroimagem e dos processos de análises contribuíram para o melhor entendimento de como a dor é processada no cérebro. Ao contrário do que se considerava no passado, o cérebro não apresenta uma área específica para a dor, mas uma rede de conexões entre áreas que também participam de outros processos. Considerase que esta rede é formada principalmente por áreas corticais e subcorticais, incluindo o córtex somatossensorial primário (S1), secundário (S2) e insular (I), o córtex cingulado anterior (CA), o córtex pré-frontal (PF) e a amígdala (APKARIAN et al, 2005).

Baseado nos fundamentos da neurociência aplicada à dor, Nijs et al (2017) estudaram possíveis alterações centrais identificadas através de ressonância magnética funcional em indivíduos com dor lombar crônica. Uma dessas alterações seria o aumento da conectividade em várias regiões cerebrais como PF, I e CA e uma interrupção na conectividade da default mode network $(D M N)$ ou, em tradução livre, no modo padrão da rede (NIJS et al, 2017). A DMN é constituída por várias regiões cerebrais que funcionam de forma sincrônica que participam da memória, monitoramento corporal interno e sua relação com ambiente externo e também modulação da percepção de dor e estímulos nocivos agudos (BALIKI et al, 2014). Os padrões de ativação cerebral de indivíduos 
saudáveis em comparação com condições dolorosas crônicas se mostrou diferente, o que poderia favorecer uma vulnerabilidade para a permanência da dor e outras comorbidades. (APKARIAN et al 2005; DERBYSHIRE et al, 2002). As diferenças encontradas se concentram em diminuição da atividade das áreas de tálamo (T) S1, S2, I e CA e aumento da atividade no PF o que demonstra que condições crônicas de dor tem componentes cognitivos e emocionais relevantes à dor aguda (APKARIAN et al 2005). Foi demonstrado também o envolvimento de um circuito cerebral emocional e límbico na transição da dor aguda para crônica e o papel das emoções na mudança da percepção da dor como uma representação sensorial para um estado emocional complexo baseado em aprendizagem (HAMMAN 2012; HASHMI et al 2013; KOBER et al 2008; LINDQUIST et al 2012).

Além das mudanças na atividade de algumas áreas do cérebro, ocorrem alterações estruturais conforme observado em um estudo com pessoas com dor lombar crônica (SCHMIDT-WILCKE et al 2006). Atualmente, diversos estudos sobre condições de dolorosas, como a fibromialgia (KUCHINAD et al, 2007), osteoartrite (GWYLIAM et al, 2009), cefaleias (SCHMIDT-WILCKE et al, 2005; KIM et al, 2008; VALFRE et al, 2008) e síndrome da dor complexa regional (GEHA et al, 2008), também identificaram modificações tanto funcionais quando estruturais do cérebro. As mudanças na substância cinzenta parecem ser provenientes de um processo de adaptação estrutural cerebral e tais mudanças correlacionadas com aumento de dor, incapacidade e anos com dor, sendo mais prevalente nas condições citadas. (APKARIAN et al, 2004; BALIKI et al, 2011; SCHMIDT-WILCKE 2008).

Outra característica da modificação no cérebro é a reorganização cortical (RC) de S1 e do córtex motor primário (M1) (NGOMO et al, 2015). Nessas áreas sensoriomotoras existe uma representação do corpo no cérebro tanto para estímulos sensoriais quanto para saídas motoras. Especificamente, S1 e S2 são responsáveis pela somatotopia, ou seja, um mapa de representação do corpo no cérebro que é responsável pelas aferências sensoriais das diferentes partes do corpo (PENFIELD, BOLDREY 1937). A representação gráfica dessa organização se dá através do "Homúnculo de Penfield" e de forma sensorial e motora quase não se difere (DALL'ORSO et al 2018). Algumas regiões do corpo são representadas de forma desproporcional no mapa somatotópico em relação a real anatomia, sendo representadas em maior proporção na topografia cortical na medida em que sua estrutura é mais ricamente inervada ou funcionalmente mais nobre (MARSHALL, MELTZOFF 2015). Os mapas corticais são dinâmicos e capazes de sofrer 
modificações e desta maneira serem reorganizados (BUONAMANO, MERZENICH 1998). A RC é oriunda do processo de neuroplasticidade que acontece ao longo da vida de forma funcional no território cortical (BOUDREAU, FARINA, FALLA, 2010). No caso das dores crônicas acontece a plasticidade mal adaptativa ocorrendo uma modificação da RC que pode ser explicada pela persistência do estímulo nociceptivo recebidos do segmento específico de dor (FLOR 1997; TSAO 2008).

A área de S1 processa as informações sensoriais recebidas da periferia, enquanto que a área de M1, de forma sincrônica, codifica a posição e executa com precisão tarefas motoras (LOTZE; MOSELEY, 2007; MARSHALL, MELTZOFF 2015). A essa relação damos o nome de esquema corporal, sendo uma representação do espaço do indivíduo que integra várias informações de entrada visual, proprioceptiva e tátil interagindo com sistemas motores para promover função (MOSELEY et al 2012). A RC dessas áreas poderia interferir na modulação sensorial da dor que inclui a localização e intensidade da dor além de contribuir para distúrbios motores também evidenciados nas condições dolorosas crônicas (KONG et al., 2013). Segundo Ngomo (2015), uma possível explicação de parte dos déficits encontrados nas tendinopatias do manguito rotador poderia ser a RC de S1 e M1.

Clinicamente podemos avaliar as manifestações de uma possível RC através da observação das tarefas motoras (ROY et al, 2017), da disfunção sensorial que pode variar de hipoestesia com diminuição da acuidade tátil ou até presença de alodínia, com percepção de dor em estímulos não dolorosos (JUOTTONEN et al, 2002), do aumento da área de dor percebida pela pessoa (FLOR, 2003; MOSELEY; FLOR, 2012) e pelos desenhos em mapas corporais (BARBERO et al, 2015) assim como pelos relatos de percepção de diminuição (MOSELEY et al, 2008) ou aumento do segmento acometido (NISHIGAMI et al 2015). Dois testes clínicos, a análise da sensibilidade discriminativa de dois pontos (teste de discriminação de dois pontos) e o teste julgamento de lateralidade, são sugeridos na tentativa de evidenciar clinicamente alterações da representatividade do corpo no cérebro que podem ter surgido em virtude da dor crônica (BRAY, MOSELEY 2014; CATLEY et al. 2013; FLOR et al 1997; STANTON et al. 2013).

O teste de discriminação de dois pontos (TDDP) é uma medida de percepção tátil originalmente descrita para verificar a distância necessária para identificação de dois pontos. Nos casos de dores crônicas, o TDDP tem sido usado como um possível marcador clínico de RC, visto que, o indivíduo deve recrutar seu mapa corporal somatotópico durante a realização do teste. $\mathrm{O}$ resultado do TDDP pode indicar a integridade ou não 
desta representação na área de S1 (BOTNMARK, TUMILTY, MANI, 2016; LOTZE; MOSELEY, 2007; PLEGER et al 2006) uma vez que a percepção precisa de estímulos táteis depende de uma somatotopia intacta (LOTZE, MOSELEY 2007). A literatura sugere a identificação de limiares maiores para discriminação de dois pontos no local acometido em comparação com controles saudáveis ou locais remotos sem dor (LUEDTKE et al 2018). Em uma revisão sistemática escrita por Catley et al. (2014) que incluiu estudos com pessoas com dor lombar crônica, síndrome de dor complexa regional e osteoartrite verificou-se uma maior distância no teste de discriminação de dois pontos. Achados similares também foram descritos nas pessoas com migrânea, (LUEDTKE et al 2018) e com dor cervical crônica (HARVIE et al. 2018). Harvie et al. (2018) ainda encontrou alterações na discriminação de dois pontos em locais distantes a queixa principal sugerindo que pode haver uma imprecisão sensorial generalizada em indivíduos com dores crônicas.

Já o julgamento de lateralidade (JL), que é a capacidade de reconhecimento de partes do corpo como pertencentes à esquerda ou à direita, envolvem processamentos cerebrais importantes para execução de uma função adequada, servindo também como um marcador clínico da integridade do esquema corporal (BRAY; MOSELEY, 2011; BRECKENRIDGE et al, 2015; MEULDERS et al. 2015; WALLWORK et al, 2015).

A incongruência entre aferência sensorial e saída motora, pode ser identificada clinicamente como as alterações do senso de posicionamento articular e consciência espacial do corpo (HEERKENS et al 2018). A performance no julgamento de lateralidade, entendida como acurácia na discriminação do lado corporal observado no menor tempo possível, é considerada como uma forma de avaliar o esquema corporal, pelo princípio de que ao julgar as imagens do segmento corpóreo, como pertencentes ao lado direito ou esquerdo, há uma rotação mental na tentativa de se posicionar na imagem (PARSON 2001). Estudos com pacientes de síndrome da dor complexa regional (MOSELEY 2004; SCHWOEBEL et al 2001), síndrome do túnel do carpo (SCHMID, COPPIETERS 2012) e osteoartrite (STANTON et al 2013) mostraram valores de tempo ampliado e acerto reduzido na identificação do segmento afetado.

Um recente estudo no qual foi avaliado o julgamento de lateralidade em 30 indivíduos sem dor no ombro (BOTNMARK et al. 2016) foram encontrados valores médios de acurácia de $94 \%$ para o lado dominante e $95 \%$ para o não dominante. Para o tempo de resposta, o valor médio foi de 1.3 segundos. Entretanto, não se sabe ao certo os 
valores consistentes de acurácia e tempo de resposta no JL para indivíduos com dor no ombro.

Outras alterações observadas em pessoas com dor crônica envolvem características que podem resultar ou ser resultado de um estresse psicológico, como sintomas depressivos (ROH et al., 2012; BAIR et al., 2003), ansiedade (CHO et al., 2013) e catastrofização (GELATLY; BECK, 2016). O estado emocional pode influenciar na percepção dolorosa visto que, áreas cerebrais relacionadas ao processamento da dor como córtex cingulado anterior e insular, aumentam sua atividade evocada (PHILLIPS et al, 2003). Além disso, a antecipação ou expectativa da dor também poderia ativar essas áreas mesmo na ausência de um estímulo nociceptivo (VILLEMURE, BUSHNELL 2002)

Muitos pacientes podem apresentar características de magnificação, cujo os sintomas parecem desproporcionais ou excessivos (LUMLEY et al., 2011). Em um recente estudo foi evidenciado a contribuição de fatores psicossociais na percepção de dor e incapacidade de indivíduos com dor crônica no ombro (MATINEZ-CALDERON et al 2018). Os achados reportam a respeito de mau gerenciamento da dor nesses indivíduos associados a uma percepção negativa dos sintomas favorecendo alterações centrais no processamento da dor (NOTEN et al 2017) e mudanças cognitivocomportamentais como medo e evitação relacionado aos movimentos do ombro, faltas no trabalho e alterações de humor (LITTLEWOOD et al 2013). Além disso é reportado na literatura a contribuição da catastrofização como outro fator que contribui para a manutenção ou exacerbação do quadro álgico, assim como ser o gatilho para início dos sintomas (LUMLEY et al., 2011).

Os pensamentos catastróficos foram definidos como uma distorção cognitiva que abrange pensamentos excessivamente negativos, desesperança e magnificação da sua condição ou sintoma (SEHN, 2012). Além da catastrofização, os afetos também parecem ser importantes para entender o contexto vivenciado pelo paciente (ZANON et al., 2013). Entende-se por afetividade a intensidade e a frequência com que as pessoas vivenciam emoções, sendo que altos escores de afeto positivos são relacionados com percepção de felicidade e como uma prevenção de psicopatologias e altos escores de afetos negativos são relacionados com ruminação, ansiedade e depressão (MILES; MACLEOD; POTE, 2004; ZANON et al., 2013).

Com base nos estudos expostos acima, faz-se necessário investigar possíveis alterações na sensibilidade discriminativa e no julgamento de lateralidade em indivíduos com dor no ombro sendo estes achados possíveis marcadores de reorganização 
cortical. De fato, é importante identificar a relação existente com outras variáveis como área de dor, incapacidade funcional, predominância de afeto negativo e catastrofização, visto que, podem influenciar na experiência de dor do indivíduo. Hipotetiza-se que os indivíduos com dor crônica, apresentem menor capacidade discriminativa de dois pontos e de julgamento de lateralidade por sofrerem reorganização cortical do mapa corporal, representado no sistema nervoso central, pelo processo de evolução da condição dolorosa, correlacionando-se positivamente com a presença de elevado escore de afetos negativos e catastrofização dos sintomas.

\section{OBJETIVOS}

\section{Objetivo primário}

Comparar a discriminação de dois pontos entre o lado acometido e não acometido e o julgamento de lateralidade dos segmentos ombro e pé em indivíduos com dor crônica unilateral não traumática no ombro.

\section{Objetivos secundários}

Verificar se o auto relato de funcionalidade do ombro (escore total do SPADI) é influenciado pela acurácia do julgamento de lateralidade do ombro e pela discriminação de dois pontos no ombro.

Verificar se a porcentagem da área corporal marcada como dolorosa é influenciada pela acurácia do julgamento de lateralidade do ombro e acurácia na discriminação de dois pontos.

Verificar se o auto relato de funcionalidade no ombro (escore total do SPADI) é influenciado pelo escore de afetos negativos e de catastrofização da dor.

Verificar se a porcentagem da área corporal marcada como dolorosa é influenciada pelo escore de afetos negativos e de catastrofização da dor. 


\section{MÉTODOS}

\section{Desenho do Estudo}

Estudo observacional, do tipo transversal e quantitativo.

\section{Aspectos éticos}

O trabalho foi submetido e aprovado pelo Comitê de Ética em Pesquisa do Centro Saúde Escola (CSE-Cuiabá) da Faculdade de Medicina de Ribeirão Preto da Universidade de São Paulo (FMRP-USP) de acordo com resolução 466/12 CNS/MS (CAAE 65423616.3.0000.5414) (Anexo A). Os voluntários foram informados sobre os objetivos e procedimentos da pesquisa e quanto aos seus direitos durante a realização da pesquisa, incluindo a garantia de total anonimato, sua liberdade de participação e possível desistência em qualquer período da pesquisa, sem qualquer punição, sendo assim, assinaram o Termo de Consentimento Livre e Esclarecido (TCLE) (Apêndice B)

\section{Amostra}

A seleção de voluntários foi realizada através da Secretaria Municipal da Saúde (SMS) da cidade de Ribeirão Preto (aprovação ofício no 4816/16) (Anexo B). As fichas triadas continham no campo diagnóstico os termos: "Dor anterior no ombro", "síndrome do impacto subacromial", "síndrome de pinçamento subacromial", "ombro doloroso", "tendinite do ombro" ou específica de tendões do manguito rotador, "bursite subacromial" ou "bursite subdeltoidea". As fichas que apresentaram informações positivas sobre condições sistêmicas como artrite reumatoide, fibromialgia e lúpus ou ainda informação sobre traumas associados, lesão nervosa periférica, luxação ou ruptura completa dos tendões do manguito rotador foram desconsideradas na triagem.

O convite para participar do estudo foi realizado inicialmente por contato telefônico com os potencialmente elegíveis para o estudo, informando brevemente sobre os objetivos do estudo, sobre a etapa seguinte de avaliação para averiguação dos critérios de inclusão e exclusão e agendando as avaliações de acordo com a disponibilidade dos que concordaram em comparecer e seguinte procedimento de coleta de dados.

Foram realizados publicações e convites para participação da pesquisa, segundo critérios estabelecidos por meio de redes sociais e rádio USP. 


\section{Critérios de Inclusão}

Foram incluídos nesse estudo os voluntários com mais de 30 anos de ambos os sexos, encaminhados para atendimento de reabilitação conservadora em clínicas de fisioterapia com queixa principal de dor no ombro de origem não traumática unilateral há mais de três meses.

\section{Critérios de Exclusão}

Foram excluídos os voluntários que relataram no momento da avaliação terem recebido diagnóstico clínico de fibromialgia, síndrome de dor complexa regional, enxaqueca ou cefaléia tensional, síndrome de fadiga crônica, disfunção temporomandibular, síndrome do intestino irritável, lesão em chicote cervical, síndrome das penas inquietas, transtornos de ansiedade (como a síndrome do pânico), sensibilidade química múltipla e depressão. Também foram excluídos, ou não incluídos, caso soubéssemos da informação previamente o agendamento inicial: a) os candidatos que apresentaram déficits cognitivos que o impediram de informar as respostas aos questionários de maneira aceitável; b) voluntários que estavam em tratamento fisioterapêutico no momento ou nos últimos seis meses; c) com comprometimento doloroso nos pés, devido ao uso do segmento para controle no teste de reconhecimento de lateralidade. Nesse estudo, foram excluídos participantes com dores no ombro ou em outras partes do corpo de origem traumática como aquelas resultantes de pós-fratura ou pós luxação nos últimos dois anos.

\section{Instrumentos de Coleta}

\section{Ficha de Avaliação}

O participante foi avaliado de acordo com o roteiro de entrevista de triagem, anamnese e exame físico do Ambulatório de Reabilitação do Complexo do Ombro ARCO (Apêndice A). Esse roteiro permite registrar informações pessoais e biopsicossociais uteis para caracterização da amostra do estudo. Desse roteiro foram utilizados os dados demográficos, a avaliação da intensidade de dor, o Índice de dor e Incapacidade do Ombro e as escalas de pensamentos catastróficos (SEHN et al., 2012) e afetos positivos e negativos (CARVALHO et al., 2013) 


\section{Índice de Dor e Incapacidade do Ombro (SPADI)}

A avaliação de auto relato de função e dor percebidos pelos pacientes foi obtida pelo escore total do questionário Índice de dor e incapacidade do ombro (SPADI) (MARTINS et al., 2010). O SPADI consiste em 13 itens distribuídos em domínio dor (cinco itens) e função (oito itens) e cada item pode ser pontuado em uma escala numérica de zero a dez pontos. No domínio dor, zero indica "sem dor" e 10 "pior dor", e no domínio da função, zero representa "sem dificuldade", e 10 "não conseguiu fazer". A pontuação final do questionário, bem como a pontuação obtida separadamente por cada domínio, foi convertida em percentagem para valores que variam de 0 a 100 , quanto maior pontuação indica a pior condição de disfunção do ombro. Este questionário foi traduzido e adaptado para população brasileira e apresentou confiabilidade teste-reteste revelando excelentes valores de Coeficiente de Correlação Intraclasse igual ou maior a 0,90 (MARTINS et al., 2010).

\section{Escala de Afetos Positivos e Negativos - PANAS}

A escala de afetos positivos e negativos (PANAS) (Anexo C) é uma escala para medir o Afeto Positivo (AP) e o Afeto Negativo (AN), definidos como dimensões gerais que descrevem a experiência afetiva dos indivíduos. A afetividade está relacionada com a maneira que os indivíduos vivenciam as emoções, sendo que na perspectiva cognitiva, os afetos influenciam a capacidade de escolha e julgamento do indivíduo. Altos níveis de AP correspondem à sensação de foco e energia do indivíduo e engajamento nas suas atividades vivenciadas através de episódios intensos e frequentes de prazer. Já a prevalência de AN pode representar sofrimento subjetivo, vivenciados através de sentimentos como raiva, culpa, medo, nervosismo e episódios intensos de desprazer. Ao investigar afetos, estamos analisando a dimensão emocional do bem-estar subjetivo (CARVALHO et al., 2013; PIRES et al., 2013; ZANON et al., 2013). A escala consiste em 20 palavras, onde 10 itens representam AP e outros 10 representam AN. A apresentação das palavras foi intercalada, sendo os AP os itens 1,3,5,7,9,11,13,15,17 e 19 e negativos os itens $2,4,6,8,10,12,14,16,18$ e 20 . A pontuação final, se dá pela soma dos itens de AP e de AN conferindo um escore de afetividade positiva e negativa sem valor de corte específico. A pontuação é avaliada pela predominância da afetividade comparada com uma população de indivíduos saudáveis que apresentou AP um escore de 33 pontos e AN 17 pontos. A PANAS foi traduzida para a versão brasileira e apresenta boa 
consistência interna com valores de alfa de Cronbach para afetos positivos de 0,88 e para afetos negativos 0,87 (CARVALHO et al., 2013).

\section{Escala de Pensamentos Catastróficos (PCS)}

A escala de pensamentos catastróficos (PCS) (Anexo D) apresenta 13 frases sobre pensamentos catastróficos relacionados a dor, e o indivíduo deve assinalar a intensidade deste pensamento em uma escala do tipo Likert de 0 a 4 pontos, onde são considerados mínimo, leve, moderado, intenso e muito intenso respectivamente. A pontuação se dá pela soma dos itens, que variam de 0 a 52 pontos com valor de corte de 30 pontos. Quanto maior a pontuação, maior a catastrofização relacionada a dor. Foi traduzida e adaptada para o português do Brasil e apresenta excelente consistência interna com alpha de Cronbach de 0,91 (SEHN et al., 2012)

\section{Teste de Discriminação de Dois Pontos (TDDP)}

O TDDP foi realizado utilizando o Aesthesiometer e Model 16023, Lafayette Instrument®. A sensibilidade discriminativa dos ombros foi avaliada em medidas realizadas na região anterior (Ponto 1), levando-se em consideração cinco centímetros a partir do acrômio e lateral (Ponto 2), levando-se em consideração a inserção distal do músculo deltoide, totalizando dois pontos de aplicação do teste em cada ombro (figura 1). Uma mínima pressão foi realizada pelo paquímetro a fim de oferecer uma sensação de toque leve no sentido horizontal. O examinador foi previamente treinado na aplicação do TDDP. Este treinamento foi realizado para melhorar o manuseio do paquímetro e praticar o leve toque na pele sem produzir abaulamento, usando as pinças para medição externa. Essas medidas não foram consideradas na presente análise de dados, pois o procedimento de aplicação sofreu modificações, como a redução do número de pontos no ombro e adaptação ao método staircase de aplicação (BOTNMARK et al, 2016; FALLING, MANI 2016; HEERKENS et al 2018; MOBERG 1990).

O método da possibilidade de 3 alternativas foi utilizado e o participante deveria relatar se sentiu um ponto, dois pontos ou se não tinha certeza da sensação. Também foram utilizados dois estímulos nulos (estímulo de um ponto) que foram randomizados entre as aplicações do TDDP para reduzir o viés do método. Para a aplicação foram utilizadas 4 rodadas dentre elas, 2 descidas e 2 subidas, sendo o método staircase adaptado levando em consideração regras de subida e descida (figura 2). O método então 
continha 2 subidas, que são aplicações com o paquímetro abrindo, 2 descidas que são aplicações com o paquímetro fechando e dois pontos nulos aplicados de maneira aleatorizada.

A regra de subida e descida foi definida no estudo piloto, ou seja, foram definidos os milímetros a serem aumentados ou diminuídos de acordo com a resposta do participante. Foi definido uma diminuição ou aumento da distância entre as pás do paquímetro de $2 \mathrm{~mm}$, sendo que nas subidas aumentava-se de $2 \mathrm{~mm}$ em $2 \mathrm{~mm}$ até o participante relatar a sensação de dois pontos e nas descidas diminuía-se de $2 \mathrm{~mm}$ em $2 \mathrm{~mm}$ até o participante relatar a sensação de 1 ponto. Em caso de incerteza por parte do participante, uma nova chance na mesma distância foi considerada e se a incerteza permanecesse foi considerado como resposta incorreta aumentando também a distância entre as pás. O teste foi iniciado na posição de $20 \mathrm{~mm}$ e as distâncias foram aumentadas até a percepção de 2 pontos. Caso o participante já identificasse a posição de $20 \mathrm{~mm}$ como sendo dois pontos, essa distância era considerada como a primeira subida e as pás eram diminuídas de $2 \mathrm{~mm}$ em $2 \mathrm{~mm}$ como informado previamente.

Foi calculado a média das 4 rodadas para estimar o limiar de discriminação do indivíduo para cada região, portanto 4 estimativas foram dadas para cada participante visto que, são 2 pontos de aplicação em cada lado.

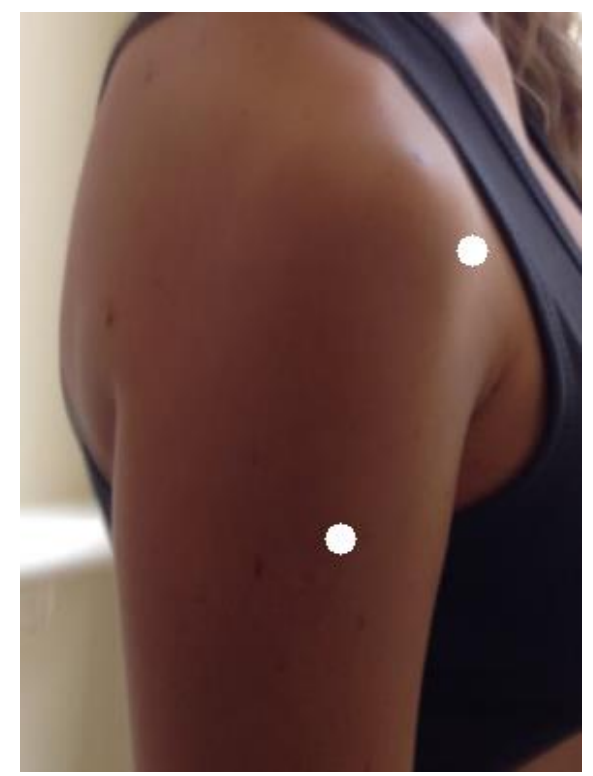

Figura 1. Pontos de aplicação do TDDP; Região anterior e superior (Ponto 1), Inserção distal do m. Deltóide (Ponto 2). Fonte: Laboratório de Análise da Postura e do Movimento Humano - LAPOMH. 


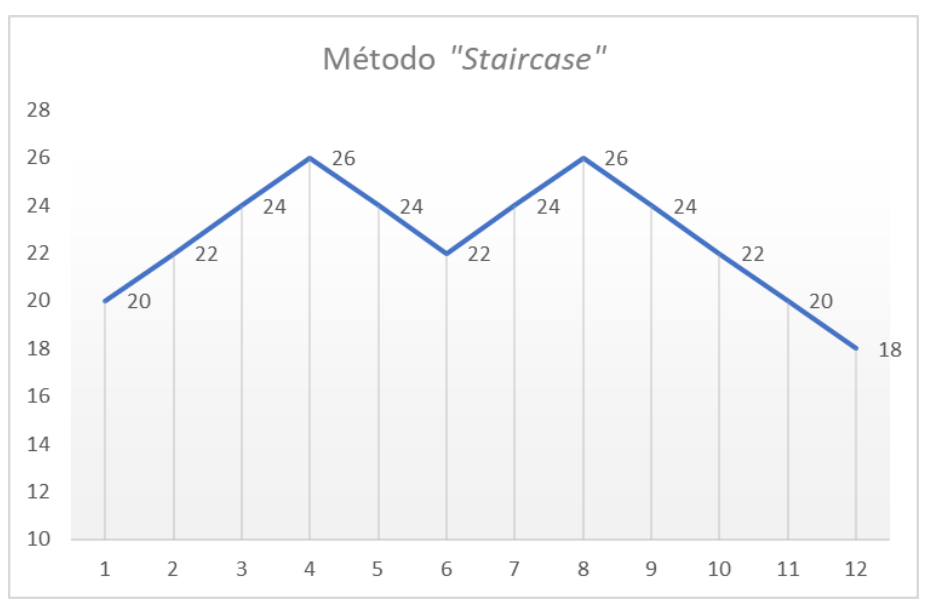

Figura 2. Aplicação do método staircase adaptado. Início na distância de $20 \mathrm{~mm}$. Os picos representam os pontos de virada onde o participante relatou sentir um ou dois pontos. Totalizando 2 subidas e 2 descidas. $\mathrm{O}$ mesmo procedimento foi realizado para o ponto 1 e 2 no ombro acometido e não acometido.

Durante o teste, de em média cinco minutos, mantivemos o participante vendado. O TDDP foi aplicado por um fisioterapeuta da equipe que se manteve cego em relação ao ombro acometido (BOTNMARK; TUMILTY; MANY, 2016; CATLEY et al; HARVIE et al 2018; VAN NES et al., 2015).

A metodologia do TDDP adaptada e utilizada nesse estudo foi avaliada de acordo com o coeficiente de correlação intraclasse para analisar a confiabilidade intraexaminador do método.

\section{Julgamento de lateralidade (JL)}

O teste de julgamento de lateralidade foi realizado utilizando os aplicativos Recognise ShoulderTM e Recognise FootTM (Neuro Orthopaedic Institute- NoiGroup, Adelaide AS, AUS), instalados em um tablet de 9,7 polegadas (Samsung® Eletronics, Galaxy Tab A, Seul, ROK)". Os aplicativos apresentaram imagens dos segmentos ombro e pé em diferentes posições e contextos, para variar a complexidade do julgamento de lateralidade, que deve ser realizado clicando na touchscreen a palavra direita ou esquerda. No aplicativo as palavras “direita" e "esquerda" estão em língua inglesa, sendo necessário explicar ao indivíduo que "left" corresponde à esquerda e "right" corresponde à direita.

O procedimento iniciou-se com familiarização da tarefa com a visualização de 30 imagens no tempo de cinco segundos cada da categoria pé. Após familiarização foi apresentado uma sequência de 30 imagens do ombro, no tempo de cinco segundos cada, 
por três repetições e o indivíduo realizou o julgamento da lateralidade. O intervalo entre os testes foi de um minuto (BOTNMARK; TUMILTY; MANY, 2016). A resposta no tempo de dois segundos é considerada normal para a região do ombro. (MOSELEY et al, 2012).

O teste com as imagens do pé foi considerado como resultados controle, uma vez que representam o reconhecimento de lateralidade de uma região remota para comparação dos resultados do ombro. Foram analisados os tempos de resposta médios e acurácia da tarefa comparado ao local remoto. O teste foi aplicado por uma fisioterapeuta da equipe que iniciou o procedimento de avaliação, sendo que esta não era cega em relação às características do indivíduo como lado acometido, história da dor e perfil psicológico. A aplicação do julgamento de lateralidade em dispositivos móveis, como tablets e celulares, teve sua confiabilidade e validade testada recentemente. Apesar das imagens do ombro não terem sido avaliadas, o julgamento de lateralidade em dispositivo móvel teve boa a excelente confiabilidade (ICC $=0,78-0,91)$ (Willians et al 2019)

\section{Mensuração da área de dor}

A mensuração da área dolorosa foi realizada por um aplicativo de desenho Sketchbook instalado em um tablet de 9,7 polegadas (Samsung® Eletronics, Galaxy Tab A, Seul, ROK)". O indivíduo marcou a área de dor através de uma caneta para tablet em imagens de mapa corporal anterior e posterior que foram importadas para o aplicativo e posteriormente analisadas através do programa Body Chart Analyser V1.6 que nos quantificou a área dolorosa em pixels (BARBERO et al, 2015). Outro estudo de confiabilidade com a área dolorosa, do papel para meio digital, já foi previamente realizado pelo grupo, o que demonstra conhecimento prévio no uso do aplicativo e melhor orientação para os indivíduos desse estudo (CASEIRO et al, 2019).

\section{Procedimentos}

\section{Coleta de dados}

Os indivíduos que concordaram em participar foram orientados quanto aos procedimento e assinaram o TCLE. Em seguida iniciaram o processo de avaliação pelo examinador 1 treinado de acordo com o roteiro do Ambulatório de Reabilitação do Complexo do Ombro (ARCO). Após anamnese e aplicação dos questionários, um segundo examinador blindado para os dados da anamnese, realizou a primeira aplicação do teste de discriminação de dois pontos. Ao finalizar, o participante foi orientado pelo 
examinador 1 a realizar o preenchimento do mapa corporal com a área de dor e quanto ao teste de julgamento de lateralidade. Uma segunda medida do TDDP, ao final do teste de JL, foi realizado pelo examinador 2 para confiabilidade intra-examinador dessa variável.

\section{Cálculo Amostral}

A estimativa do tamanho da amostra foi baseada na correlação utilizada pelo estudo prévio de Botnmark, Tumilty e Mani (2016), que levou em consideração uma correlação de $r=45$, um poder de $80 \%$ e um $\alpha 0,05$ que sugeriu 29 sujeitos.

\section{Análise estatística}

A análise estatística proposta para este estudo foi realizar uma análise descritiva de todas as variáveis, sendo os dados apresentados na forma de média, desvio padrão, intervalo de confiança e frequência absoluta e relativa. A priori para o TDDP foi utilizado o modelo de regressão linear com efeitos mistos. Esse modelo considera um efeito aleatório por indivíduo, informando que o mesmo possui medidas tomadas no lado com dor e no lado sem dor e em duas regiões diferentes. Para o JL foi realizado o teste $\mathrm{t}$ dependente para comparar o tempo médio e a acurácia de julgamento das imagens do teste entre os segmentos ombro e pé. Levou-se em consideração nível de significância de 95\% e as análises foram realizadas pelo software SPSS 2.0, R Core Team(2016) e SAS 9.3. A posteriori foi verificado a relação entre as variáveis através da regressão linear e correlação de Pearson

Foi analisado o coeficiente de correlação intraclasse (ICC), erro padrão da medida (EPM) e mínima mudança detectável (MMD) para avaliar a confiabilidade intraexaminador do método TDDP. O ICC foi calculado levando-se em consideração intervalo de confiança de $95 \%$ para a média de 3 aplicações sendo o $\mathrm{ICC}_{3, \mathrm{k}}$ (aleatório de duas vias e concordância absoluta) realizado por um único avaliador. A interpretação do ICC foi baseada em valores (>0,90) como excelente confiabilidade, valores entre 0,80 e 0,89 como boa confiabilidade; entre 0,70 e 0,79 moderada confiabilidade e $(<0,70)$ baixa confiabilidade (COOLS, 2014; WEIR 2005). 


\section{Resultados}

O processo para recrutamento dos voluntários teve início em agosto de 2017 e foram selecionadas 276 guias de pacientes com idade maior que 30 anos e queixa de dor no ombro. Por meio dessas guias, 64 indivíduos foram excluídos antes da triagem em virtude de apresentarem a informação de dor bilateral ou instabilidade no ombro. Sendo assim, foram selecionadas 212 guias elegíveis para a triagem. Dos indivíduos elegíveis,167 foram excluídos na triagem e a maior perda ocorreu devido à algum comprometimento dos pés ou diagnóstico favorável a mecanismos de sensibilização central. Assim, 45 guias foram disponibilizadas para avaliação e 12 encaminhamentos novos para fisioterapia foram recebidos para avaliação da Secretaria Municipal de Saúde. No momento da avaliação, 10 voluntários foram excluídos e a amostra final foi composta por 52 voluntários (Figura 3).

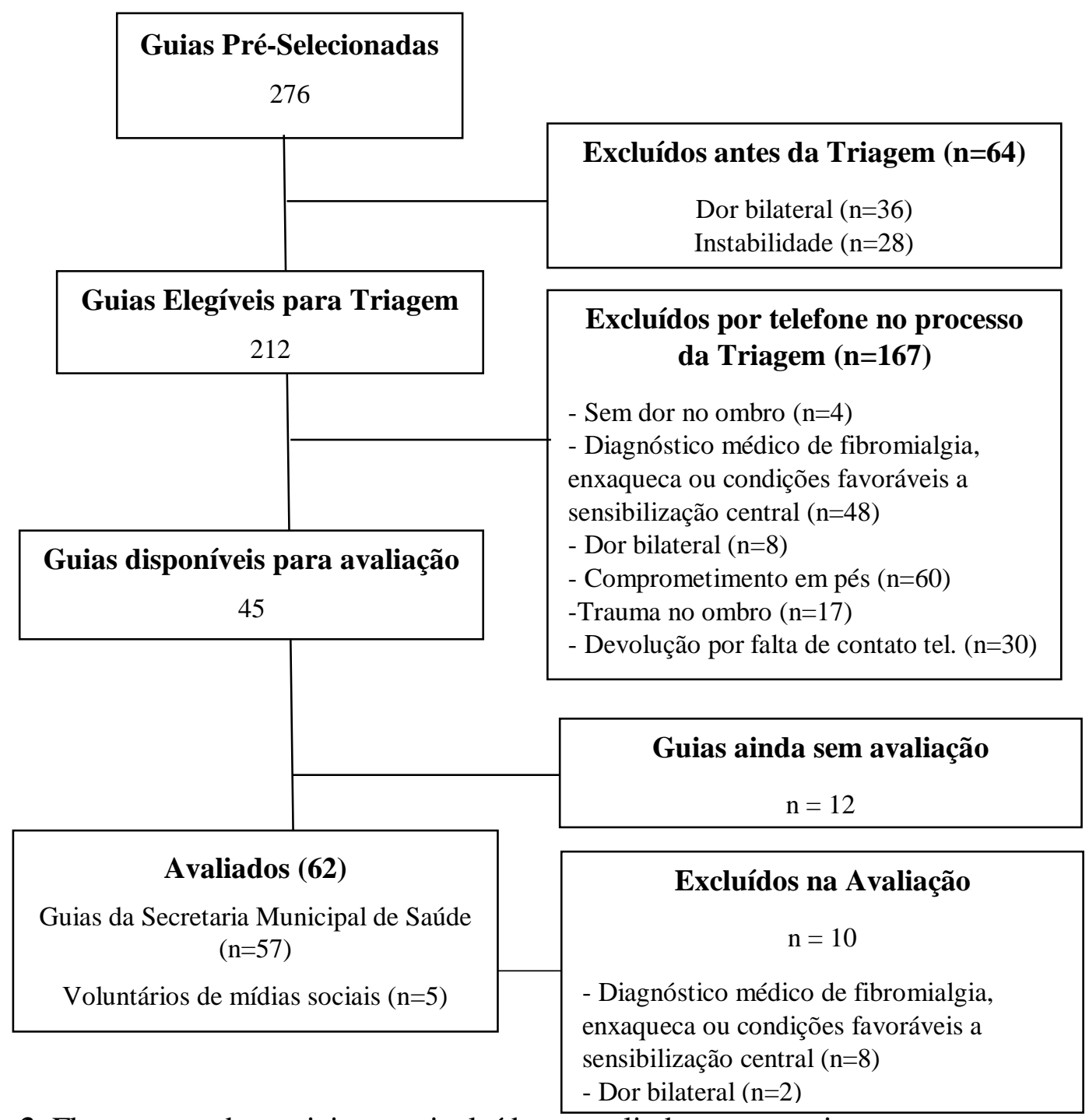

Figura 3: Fluxograma de participantes incluídos e avaliados na pesquisa. 
A amostra total foi composta por 37 mulheres e 15 homens com dor crônica unilateral do ombro, de origem não traumática, com média de idade de 54,08 (DP=9,25) anos, tempo médio de sintoma 39,87 ( $\mathrm{DP}=39,86)$ meses e maior frequência de acometimento do ombro direito. A média da pontuação total do SPADI foi de 48,56 $(\mathrm{DP}=25,98)$, dos afetos positivos 35,8 (DP=8,51) e afetos negativos 23,48 (DP=8,76) e de catastrofização 23,88 ( $\mathrm{DP}=11,91)$. A Tabela 1 apresenta os dados de caracterização dos 52 voluntários envolvidos no estudo.

Tabela 1. Caracterização da amostra e escores dos questionários de incapacidade, afetividade e catastrofização, $\mathrm{n}=52$ indivíduos.

\begin{tabular}{lccc}
\hline & n (\%) & Média & DP \\
\hline Sexo & $37(71,16)$ & & \\
Mulher & $15(28,84)$ & & \\
Homem & & \\
Idade & & 54,08 & 9,25 \\
Lado Acometido & $40(76,92)$ & & \\
Direito & $12(23,07)$ & & \\
Esquerdo & & 39,87 & 39,86 \\
Tempo de Sintoma (meses) & 48,56 & 25,98 \\
SPADI (0-100) & & 35,8 & 8,51 \\
PANAS Positivo (10-50) & & 8,76 \\
PANAS Negativo (10-50) & & 23,48 & 11,91 \\
PCS (0-52) & & 23,88 & 3,04 \\
END na Avaliação (0- 10) & & 2,2 & \\
\hline
\end{tabular}

SPADI: índice de dor e incapacidade no ombro; PANAS: escala de afetos positivos e negativos; PCS: escala de pensamentos catastróficos; END: escala numérica de dor.

Os resultados do TDDP estão apresentado na Tabela 2. A média de discriminação para o ombro acometido no ponto 1 (aspecto anterior do ombro), foi de 28,08 ( $\mathrm{DP}=11,04)$ mm e para o ombro não acometido $27,77(\mathrm{DP}=11,34)$. No ponto 2 (região próxima a inserção do deltoide), a média de discriminação de dois pontos foi de 27,86 (DP=9,92) e para o ombro não acometido $26,87(\mathrm{DP}=9,76) \mathrm{mm}$. Entretanto, as diferenças entre as médias de TDDP entre ombro acometido e não acometido não foram estatisticamente significativas. A quantidade de indivíduos que responderam o TDDP variou entre os 
lados. No lado acometido 3 indivíduos não perceberam o toque do paquímetro na pele enquanto que no lado não acometido, 2 conforme demonstrado na tabela 2. O TDDP apresentou excelente confiabilidade com ICC: 0,86 (IC 95\% 0,74;0,92) para o ponto $1 \mathrm{e}$ boa confiabilidade com ICC: 0,77 (IC 95\% 0,59;0,87) para o ponto 2 no ombro acometido. No ombro não acometido foi encontrado baixa confiabilidade para o ponto 1 com ICC: 0,40 (IC 95\% -0,07;0,66) e ponto 2 com ICC: 0,50 (IC 95\% 0,10;0,71), como demonstrado na tabela 3 .

Tabela 2. Média da distância (mm) e comparação entre ombro acometido e não acometido no TDDP.

\begin{tabular}{lcccccc}
\hline & \multicolumn{1}{c}{$\begin{array}{c}\text { Ombro } \\
\text { Acometido }\end{array}$} & $\begin{array}{c}\text { Ombro não } \\
\text { acometido }\end{array}$ & \\
\hline Ponto 1 & n & Média (DP) & n & Média (DP) & $\boldsymbol{p}$ & $\mathbf{9 5 \% ~ I C ~}$ \\
Ponto 2 & 49 & $28,08(11,04)$ & 50 & $27,77(11,34)$ & 0,58 & $-1,18 ; 2,10$ \\
\hline & 49 & $27,86(9,92)$ & 50 & $26,87(9,76)$ & 0,17 & $-0,50 ; 2,77$ \\
\hline
\end{tabular}

TDDP: Teste de discriminação de dois pontos; Lado: acometido e não acometido; Ponto 1: região ântero-superior do ombro; Ponto 2: sobre a inserção do músculo deltóide; n: número de indíviduos que responderam o TDDP; $\mathbf{p}$ : valor de $\mathrm{p}(0,05)$ da comparação das distâncias entre ombro acometido e não acometido nos Pontos 1 e 2; IC: intervalo de confiança da média das diferenças.

Tabela 3. Análise da confiabilidade intra-examinador no TDDP

\begin{tabular}{lcccccc}
\hline & \multicolumn{3}{c}{ Ombro acometido } & \multicolumn{3}{c}{ Ombro Não Acometido } \\
\hline & ICC $3, \mathbf{k}$ & EPM & MMD & ICC 3,k & EPM & MMD \\
\hline Ponto 1 & 0,86 & 3,67 & 10,17 & 0,40 & 7,60 & 21,06 \\
Ponto 2 & 0,77 & 4,70 & 13,02 & 0,50 & 6,94 & 19,23 \\
\hline
\end{tabular}

TDDP: Teste de discriminação de dois pontos; Ponto 1: região ântero-superior do ombro; Ponto 2: sobre a inserção do músculo deltóide; ICC: coeficiente de correlação intraclasse; EPM: erro pdrão da medida; MMD: mínina mudança detectável.

No resultado do JL, a média do tempo de três medidas para o ombro acometido foi 1,51 (DP=0,37) segundos e para o segmento pé foi de 1,47 (DP=0,48) segundos. Ao analisarmos a média da porcentagem de acertos, também de três medidas, a média para o ombro acometido foi de 90,47 ( $\mathrm{DP}=8,32)$ e para o pé a média da porcentagem de acertos foi $90,87(\mathrm{DP}=13,14)$. A comparação entre os segmentos foi realizada por meio do teste $t$ de Student dependente pelo qual, não foi evidenciado diferença estatisticamente 
significativa no tempo de resposta e no percentual de acertos nas imagens do ombro e do pé (Tabela 4).

Tabela 4. Média de tempo e acertos no julgamento de lateralidade e comparação entre os segmentos ombro e pé, $\mathrm{n}=52$ indivíduos.

\begin{tabular}{ccccc}
\hline & Ombro & Pé & $\boldsymbol{p}$ & IC 95\% \\
\hline & Média (DP) & Média (DP) & & \\
\hline Tempo (s) & $1,51(0,37)$ & $1,47(0,48)$ & 0,59 & $-0,10 ; 0,18$ \\
Acertos $(\%)$ & $90,47(8,32)$ & $90,87(13,44)$ & 0,80 & $-3,72 ; 2,90$ \\
\hline
\end{tabular}

Ombro: segmento acometido; Pé: segmento controle para o julgamento de lateralidade; média: na variável tempo e acerto considerado a média de três medidas do JL; p: valor de p $(0,05)$ da comparação do tempo e acerto dos segmentos ombro e pé; IC: intervalo de confiança da média das diferenças para comparações do tempo e acerto dos segmentos ombro e pé.

Ao analisar a relação entre as variáveis deste estudo, investigou-se a capacidade dos testes e questionários colhidos predizerem incapacidade, avaliada pelo SPADI, assim como a porcentagem da área corporal marcada como dolorosa. Não foi encontrado relação preditiva entre elas (Tabela 5) e (Tabela 6).

Tabela 5. Modelo de regressão linear múltipla com área corporal como variável dependente, $\mathrm{n}=52$ indivíduos.

\begin{tabular}{cccc}
\hline & $\begin{array}{c}\text { Coeficiente } \\
\text { Estimado }\end{array}$ & Erro Padrão & $\boldsymbol{p}$ \\
\hline Intercepto & -12.18 & 8.20 & 0.14 \\
Ponto 1 & 0.05 & 0.05 & 0.34 \\
Ponto 2 & -0.009 & 0.06 & 0.88 \\
Acerto & 2.75 & 1.49 & 0.07 \\
Tempo & 0.11 & 0.07 & 0.12 \\
\hline
\end{tabular}

Ponto 1: região ântero-superior do ombro; Ponto 2: sobre a inserção do músculo deltóide; Acerto: porcentagem de acerto no teste de julgamento de lateralidade; Tempo: tempo em segundos no teste de julgamento de lateralidade. 
Tabela 6. Modelo de regressão linear múltipla com incapacidade como variável dependente, $\mathrm{n}=52$ indivíduos.

\begin{tabular}{cccc}
\hline & $\begin{array}{c}\text { Coeficiente } \\
\text { Estimado }\end{array}$ & Erro Padrão & $\boldsymbol{p}$ \\
\hline Intercepto & 65.81 & 62.30 & 0.29 \\
Ponto 1 & 0.20 & 0.43 & 0.63 \\
Ponto 2 & -0.17 & 0.47 & 0.70 \\
Acerto & 8.10 & 11.42 & 0.48 \\
Tempo & -0.32 & 0.54 & 0.55 \\
\hline
\end{tabular}

Ponto 1: região ântero-superior do ombro; Ponto 2: sobre a inserção do músculo deltóide; Acerto: porcentagem de acerto no teste de julgamento de lateralidade; Tempo: tempo em segundos no teste de julgamento de lateralidade.

Ao avaliar o escore do PCS e do PANAS Negativo e sua relação com a incapacidade relacionada a dor no ombro e porcentagem da área corporal marcada como dolorosa, foi evidenciado pela análise de regressão linear simples que a catastrofização da dor foi capaz de predizer incapacidade relacionada a dor no ombro, mas não aumento de área corporal dolorosa para indivíduos com dor unilateral não traumática com predomínio nociceptivo da dor (Tabela 7) e (Tabela 8).

Tabela 7. Modelo de regressão linear simples com incapacidade como variável dependente, $\mathrm{n}=52$ indivíduos.

\begin{tabular}{cccc}
\hline & $\begin{array}{c}\text { Coeficiente } \\
\text { Estimado }\end{array}$ & Erro Padrão & $\boldsymbol{p}$ \\
\hline PCS & 0.8575 & 0.2835 & $0.003^{*}$ \\
PANAS n & 0.7008 & 0.4055 & 0.09
\end{tabular}

PCS: questionário de catastrofização relacionada a dor; PANAS n: questionário de afetividade negativa; $\mathbf{p}$ : valor de p $(0,05) ; *$ : valores estatisticamente significativos.

Tabela 8. Modelo de regressão linear simples com área corporal como variável dependente, $\mathrm{n}=52$ indivíduos.

\begin{tabular}{cccc}
\hline & $\begin{array}{c}\text { Coeficiente } \\
\text { Estimado }\end{array}$ & Erro Padrão & $\boldsymbol{p}$ \\
\hline PCS & 0.08970 & 0.04489 & 0.0515 \\
PANAS n & 0.03619 & 0.06588 & 0.5855 \\
\hline
\end{tabular}

PCS: questionário de catastrofização relacionada a dor; PANAS n: questionário de afetividade negativa; $\mathbf{p}$ : valor de $\mathrm{p}(0,05)$. 


\section{Discussão}

Considerando a alta incidência de dor crônica musculoesquelética no ombro e os desafios no manejo de possíveis alterações estruturais cerebrais nesses indivíduos, o objetivo deste estudo foi analisar e comparar testes clínicos de fácil aplicabilidade para identificar essas alterações em ambiente clínico pelo fisioterapeuta. O TDDP é apresentado na literatura como um desses instrumentos, porém com grande variabilidade nos métodos de aplicação e instrumentos utilizados (CATLEY et al., 2014). Para esse estudo, o método de aplicação se mostrou com excelente confiabilidade para o lado acometido porém com fraca confiabilidade para o lado não acometido.

A aplicação do TDDP, assim como a confiabilidade intra e inter examinador, é amplamente discutida na literatura em virtude dos diversos tipos de protocolo. Harvie et al (2018) realizaram o TDDP na região cervical de indivíduos saudáveis e utilizaram o instrumento Vernier Digital Calipter, similar ao utilizado nesse estudo. Foi encontrado excelente confiabilidade $(\mathrm{ICC}=0.85,95 \% \mathrm{CI}(0.67 ; 0.94)$ porém o protocolo de aplicação se diferenciou na quantidade de subidas e descidas do método staircase. A confiabilidade intra examinador do TDDP ainda pode variar em indivíduos saudáveis de (ICC=0,500,90) e os estudos diferem em local e protocolo de aplicação do teste (ADAMCZYK et al., 2016; ADAMCZYK, LUEDTKE, SZIKSZAY 2018; CATLEY et al., 2013; MARCUZZI et al., 2017). Para indivíduos sintomáticos Ehrenbrusthoff et al., (2018a) afirmam não haver estudos de confiabilidade do TDDP com qualidade metodológica adequada para serem incluídos em revisões sistemáticas com protocolos estabelecidos, sendo necessário mais estudos com indivíduos sintomáticos, com parâmetros da aplicação adequadamente reportados (EHRENBRUSTHOFF et al., 2018b). Nós acreditamos que é plausível que haja fatores que influenciem diretamente no resultado do TDDP e em sua confiabilidade, como ambiente de aplicação, temperatura e barulhos externos, que não foram controlados, assim como variáveis indivíduais como cansaço, dor e falta de concentração, já que o protocolo total de aplicação das variáveis deste estudo variou em um período de em média 1 hora e 30 minutos. Além disso, os indivíduos do estudo eram predominantemente destros, o que nos leva a hipótese de que a dominância poderia ser um fator para melhor confiabilidade no lado acometido, podendo favorecer no processo de aprendizagem sistematizada da aplicação. Sims et al., (2015) considerou a dominância ao avaliar o TDDP em indivíduos músicos e não músicos e encontrou menor distância no lado dominante para o grupo de músicos de harpa e guitarra, podendo esse ser um fator 
que influencie também a confiabilidade. Até o presente momento, não há na literatura estudos que avaliaram a confiabilidade do TDDP em individuos sintomáticos, levando em consideração a influência da dominância no resultado assim como a aprendizagem sistematizada do teste e a comparação de um lado em relação ao outro.

Esse é o primeiro estudo com uma amostra expressiva de indivíduos sintomáticos que avaliou um protocolo de TDDP para quantificar a distância média e comparar os lados acometidos e não acometidos de indivíduos com dor crônica unilateral não traumática no ombro.

Estudos prévios apresentam dados distintos em relação a distância do TDDP para o ombro. Heerkens et al., (2018) encontraram como distância média, para o lado acometido de indivíduos com dor no ombro, de $48 \mathrm{~mm}$ em comparação com o lado não acometido de $42 \mathrm{~mm}$, e sem diferenças estatisticamente significativas. Além disso, o estudo apresenta limitações quanto a quantidade de sujeitos avaliados; apenas 4 indivíduos com dor no ombro e diferenças no protocolo de aplicação em relação a esse estudo.

O TDDP na região do ombro também foi avaliado em indivíduos assintomáticos e seu valor médio mostrou-se com grande variabilidade (16,5mm a 47,8mm) (KOO et al., 2016; BOTNMARK et al., 2016). Valores menores de discriminação de dois pontos foram atribuídos a uma amostra de jovens adultos com idade média de 22,5 anos, o que corrobora com dados na literatura que associam melhor discriminação em indivíduos mais jovens (SHIMOKATA, KUZUYA 1995; BOWDEN, MCNULTY 2013).

Nossos resultados encontram-se entre os valores reportados previamente na literatura e assim como Heerkens et al., (2018) também não foi encontrado diferença estatisticamente significativa entre os ombros. Em um estudo de Stanton et al., (2013) que avaliou indivíduos com osteoartrite de joelho, a distância do TDDP também não apresentou diferença estatisticamente significativa entre os lados. Pleger et al., (2006) e Lewis J. e Schweinhardt P. (2012) identificaram uma diferença estatisticamente significativa no TDDP entre os lados acometido e não acometido porém foram estudos que avaliaram indivíduos com síndrome da dor complexa regional. Nós acreditamos que essa diferença possa existir em uma amostra de indivíduos com predomínio de dor nociplástica, susceptível a reorganização cortical e consequente distorção sensorial, sendo possivel identificar e captar essa dimensão clinicamente (TREEDE R. D 2018). A diminuição na acuidade tátil desses indivíduos é facilmente explicada quando olhamos as possíveis alterações centrais através de uma ruptura do potencial evocado a nível de S1 
(PLEGER et al., 2001; STANTON et al., 2013), porém como reportado por Catley et al., (2014) apesar do déficit da acuidade tátil ser associado na literatura para algumas condições dolorosas crônicas ainda é incerto o ponto onde essa deficiência se torna clinicamente relevante. Além disso, vale ressaltar as diversas maneiras e protocolos existentes nos estudos a respeito da aplicação do TDDP, o que dificulta o clínico tomar uma decisão referente ao melhor modelo a ser usado na pratica clínica.

Seguindo o mesmo raciocínio, a literatura sugere que indivíduos com dor crônica poderiam ter uma tarefa de julgamento de lateralidade prejudicada, em virtude da necessidade da integridade do esquema corporal na realização da mesma (BRECKENRIDGE et al., 2018). O estudo de Breckenridge et al., (2017), avaliou a confiabilidade o JL para as imagens do ombro em uma amostra de indivíduos saudáveis. Valores normativos de tempo de resposta e acurácia foram determinados. Para indivíduos sem dor no ombro o tempo de resposta médio foi de 1,73 segundos e para acurácia de 93,8\%. Em comparação aos nossos resultados, em indivíduos com dor, os resultados são similares, já que se trata de uma população com baixa intensidade de dor no momento da avaliação o que poderia influenciar na execução do teste. Outra hipótese que poderia influenciar no resultado, seria a composição de uma amostra de indivíduos com dor crônica com predomínio de aspectos de sensibilização central, o que não foi o caso desse estudo, sendo critério de exclusão. Nos acreditamos que esse perfil de paciente pode apresentar mais dificuldade em realizar a tarefa de julgamento, por ser um paciente mais susceptivel a reorganização das representações corporais, como falado previamente (MOSELEY, GALLAAGHER, GALLACE 2012). No caso do nosso estudo, ao comparar segmentos distintos, acometido e não acometido, não foi encontrado diferenças estatisticamente significativas na acurácia o no tempo de resposta. Esses achados concordam com dados prévios na literatura como demonstrado no estudo de Breckenbridge et al., (2018) que evidenciou que para o membro superior não houve diferenças no tempo de resposta de indivíduos com dor unilateral (SCHMID, COPPIETERS 2012; REINERESMANN et al., 2012). Já para a acurácia, os dados da literatura são divergentes em relação a esse estudo. Schmid e Coppieters encontraram menor acurácia no segmento acometido para indivíduos com síndrome do túnel do carpo unilateral enquanto que para nossa amostra, não houve diferença na acurácia entre os segmentos ombro e pé. Entretanto ainda devemos olhar com cautela para os resultados de lateralidade em virtude das diferentes perspectivas atribuidas a esses dados. Punt D. (2017) alerta sobre o assunto colocando em pauta aspectos relacionados ao processo de 
julgamento de lateralidade. Punt questiona se seria essa uma tarefa relacionada a integridade do esquema corporal, relação entre inputs sensoriais e outputs motores, ou apenas uma capacidade do indivíduo de codificar espacialmente áreas corporais, sendo esse um processo de descrição estrutural do corpo pois leva em consideração o input visual e autotopagnosia (BUXBAUM, COSLETT 2001; RUMIATI et al., 2009). Além disso, Punt ainda ressalta que de alguma maneira, ao realizar o julgamento de lateralidade, e comparar o tempo de reposta, deveríamos controlar a complexidade das imagens, levando em consideração a quantidade de informação visual que cada imagem oferece (Ex. A imagem do ombro em posição neutra é diferente do ombro em flexão e abdução). De qualquer maneira, ainda não temos estudos que determinem escores do JL que consigam identificar clinicamente essas possíveis alterações, assim como valores de mínima diferença clínicamente importante para usarmos o JL também como estratégia de tratamento.

Ainda foi objeto de análise desse estudo identificar possíveis relações entre as variáveis acima citadas ao ponto de sabermos se uma poderia predizer a outra em algum sentido. Um dos nossos objetivos era verificar as relações entre o tamanho da área dolorosa e a incapacidade relacionada a dor no ombro e a distância no TDDP assim como tempo e acurácia no JL. Poucos estudos na literatura fizeram as mesmas relações e com diferentes protocolos de aplicação. Não foi encontrado nenhuma relação entre essas variáveis no nosso estudo, ou seja, o resultado do TDDP e do JL não foi capaz de predizer ou influenciar o tamanho da área dolorosa e a incapacidade. Adanczyk et al., (2018) conseguiram identificar uma relação entre a distância TDDP e área dolorosa em dois casos de pacientes com dor lombar crônica, mas não foi objetivo do estudo identificar se a distância do TDDP poderia predizer uma maior área de dor. Moseley L. (2008) ao analisar indivíduos com dor lombar crônica e solicitar que desenhassem a área dolorosa, demonstrou que os pacientes tinham dificuldade em delinear a região dolorosa, demonstrando uma distorção da imagem corporal, relacionada com piores valores do TDDP, mas também não foi objetivo desse estudo identificar uma relação dependencia entre as variáveis. Até o presente momento não temos dados na literaruta que confirmem ou refutem os dados encontrados nesse estudo quanto aos valores da relação entre a área dolorosa e sua relação com as outras variáveis. Vale ressaltar novamente que novos subgrupos de indivíduos precisam ser analisados, já que outros aspectos podem influenciar a quantidade de área dolorosa e de fato influenciar nos resultados do TDDP e no JL. 
Outros aspectos que ainda foram de interesse do nosso estudo, foram fatores psicossociais. Atualmente, já se sabe sobre os desafios em manter ganhos na reabilitação na presença de catastrofização relacionada a dor (MOORE et al., 2016), assim como sobre o risco de mau prognóstico na presença do mesmo (KIBLER et al., 2018; THORPE et al., 2018). O que nosso estudo demonstrou relevante e válido com o que temos de evidência sobre o assunto, foi que a presença da catastrofização relacionada a dor pôde predizer uma maior incapacidade em indivíduos com dor no ombro. Não foi possível identificar uma relação entre fatores psicossociais e área corporal dolorosa. Essa relação se mostra conflitante na literarura em virtude dos dinstitos protocolos para se analisar extensão da área dolorosa (REIS et al., 2018). Em virtude disso, para esse estudo foi utilizado o protocolo de análise confiável para quantificar a área dolorosa, proposto por Caseiro et al., (2019), porém são necessários mais estudos com amostras significativas na quantidade de indivíduos com dor e sem dor no ombro para que pudéssemos estratificar os tipos de dor e possíveis correlações.

Pesquisas futuras são sugeridas no sentido de identificar a diferença no JL e no TDDP entre populações com e sem dor no ombro. Além disso, para os indivíduos com dor crônica unilateral não traumática no ombro, identificar as diferenças entre as populações com predomínio de dor nociceptiva, neuropática e nociplástica e sua relação com a área de dor, incapacidade e fatores psicossociais.

O presente estudo apresenta algumas limitações que devem ser controladas para pesquisas futuras. A análise de confiabilidade foi realizada entre a primeira e a segunda medida do TDDP, não havendo uma medida inteira de aplicação apenas para familiarização da aplicação. Nossa sugestão é que pesquisas futuras levem esse detalhe em consideração, avaliando a confiabilidade entre a segunda e a terceira aplicação do TDDP. Também não houve controle de variáveis como dominância e lado acometido para pareamento da amostra de sintomáticos. Além disso, por se tratar se testes clínicos que exigem alta concentração do paciente e do terapeuta, variáveis como ambiente, temperatura da sala e tempo de aplicação de outras variáveis devem ser obrigatoriamente controladas, o que não foi o caso do nosso estudo. Novos estudos são necessários apenas com a aplicação isolada desses testes, para não haver influência de cansaço e desconcentração já que se trata de uma população de indivíduos sintomáticos. 


\section{Conclusão}

De acordo com nossos resultados, não foi encontrado diferença significativa na distância do TDDP entre os ombros e no JL entre o ombro e pé de indivíduos com dor crônica unilateral não traumática no ombro. Por meio dos nossos dados, foi possível identificar que a presença de catastrofização é capaz de predizer a incapacidade relacionada a dor no ombro. 


\section{REFERÊNCIAS}

1. ADAMCZYK W. et al. The point to point test: a new diagnostic for measuring lumbar tactile acuity? Inter and intra-examiner reliability study of pain free subjects. Manual therapy v. 22 p. 220-226. 2016.

2. ADAMCZYK W. et al. Sensory dissociation in chronic low back pain: Two case reports. Physiother Theory Pract v. 34, n. 8, p. 643-651. 2018.

3. APKARIAN A. V et al. Chronic back pain is associated with decreased prefrontal and thalamic gray matter density. J Neurosci v. 24, p. 10410-10415. 2004.

4. APKARIAN A. V. et al. Human brain mechanisms of pain perception and regulation in health and disease. Eur J Pain v. 9, p. 463-484, 2005.

5. BAIR M. J. et al. Depression and pain comorbity. Arch Intern Med v. 163, p. 2433-2445, 2003.

6. BALIKI M et al. Brain morphological signatures for chronic pain. PLoS ONEv. 6, n. 10. 2011.

7. BALIKI M. et al. Functional reorganization on the default mode network across chronic pain conditions. Plos One v. 2, n. 2. 2014.

8. BARBERO M. et al. Test-retest reliability of pain extent and pain location using a novel method for pain drawing analysis. Eur J Pain v. 19, n. 8, p. 1129-1138. 2015

9. BORSTAD J., WOESTE C. The role of sensitization in musculoskeletal shoulder pain. Braz J Phys Ther v. 19, n.4, p. 251-256, 2015.

10. BOTNMARK I., TUMILTY S., MANY R. Tactile acuity, body schema integrity and physical performance of the shoulder: A cross-sectional study. Manual Therapy v. 23, p. 9-16, 2016.

11. BOUDREAU A. A., FARINA D., FALLA D. The role of motor learning and Neuroplasticity in designing rehabilitation approaches for Musculoskeletal pain disorders. Manual Therapy v.15, p. 410-414. 2010.

12. BUONAMANO D. V., MERZENICH M. M. Cortical plasticity: From synapses to maps. Annu. Rev. Neurosci v. 21, p. 149-86. 1998.

13. BOWDEN J. L., MCNULTY P. A. Age-related changes in cutaneous sensation in the healthy human hand. AGE, v. 35, p.1077-1089, 2013.

14. BRAY H., MOSELEY G. L. Disrupted working body schema of the trunk in people with back pain. Br J Sports Med v. 45, p. 168-73, 2011.

15. BRECKENRIDGE J. D. et al. Shoulder left/right judgement task: development and establishment of a normative dataset. Physiotherapy v. 101(Suppl. 1), p. 169-70, 2015.

16. BRECKENRIDGE J. D. et al. The development of a shoulder specific left/right judgement task: Validity \& reliability. Musculoskeletal Science and Practice, v. 28, p, 39 e 45, 2017.

17. BRECKENRIDGE J. D. et al. Do people with chronic musculoskeletal pain have impaired motor imagery? A meta-analytical systematic review of the left/right judgement task. J Pain, v. 20, n. 2, p. 119-132, 2019.

18. BUXBAUM L. J. COSLETT H. B. Specialised structural descriptions for human body parts: Evidence from autotopagnosia. Cogn Neuropsychol. v.18, n. 4, p. 289-306, 2001. 
19. CASEIRO M. et al. From Paper to Digitalized Body Map: A Reliability Study of the Pain Area. Pain Practice, 2019.

20. CARVALHO H. W. Structural validity and reliability of the Positive and Negative Affect Schedule (PANAS): Evidence from a large Brazilian community sample. Revista Brasileira de Psiquiatria v. 35, p. 169-172, 2013.

21. CATLEY M. et al. Is Tactile Acuity Altered in People With Chronic Pain? A Systematic Review and Meta-analysis. The Journal of Pain v. 15, N. 10,p. 985-1000, 2014.

22. CATLEY M. et al. Assessing tactile acuity in rheumatology and musculoskeletal medicine-how reliable are two-point discrimination tests at the neck, hand, back and foot? Rheumatology v. 52, p. 1454-1461. 2013

23. CHO C. H. et al. Is shoulder pain for three months or longer correlated with depression, anxiety, and sleep disturbance? J Shoulder Elbow Surg v. 22, p. 222-228, 2013.

24. COOLS A. M. et al. Measuring shoulder external and internal rotation strength and range of motion: comprehensive intra-rater and inter-rater reliability study of several testing protocols. J Shoulder Elbow Surg v. 23, p. 1454-146, 2014.

25. DALL'ORSO S. et al. Somatotopic Mapping of the Developing Sensorimotor Cortex in the Preterm Human Brain. Cerebral cortex v. 28, P. 2507- 2515. 2018.

26. DERBYSHIRE S. et al. Cerebral Responses to Noxious Thermal Stimulation in Chronic Low Back Pain Patients and Normal Controls. NeuroImage v. 16, p. 158-168. 2002.

27. EHRENBRUSTHOFF K. et al. A systematic review and meta-analysis of the reliability and validity of sensorimotor measurement instruments in people with chronic low back pain. Musculoskeletal Science and Practice v. 35, p. 73-83. 2018a.

28. EHRENBRUSTHOFF K. et al. Reply to the letter to the editor YMATH_2018_15: “Two-point discrimination and the low back pain: Not as unreliable as it seems, but what about standardized procedures?" regarding our article MSKSP_168:"A systematic review and meta analysis of the reliability and validity of sensorimotor measurement instruments in people with chronic low back pain"

Musculoskelet Sci Pract. v. 35, e112-e113. 2018 b.

29. FLOR H., BRAUN C., ELBERT T., BIRBAUMER N. Extensive reorganization of primary somatosensory cortex in chronic back pain patients. Neurosci Lett v. 224, p. 5-8, 1997.

30. FLOR H. Cortical reorganisation and chronic pain: implications for Rehabilitation. J Rehabil Med, v. 41, p. 66-72, 2003

31. GEHA P.Y et al. The brain in chronic CRPS pain: abnormal gray-white matter interactions in emotional and autonomic regions. Neuron v. 60, p. 570-581. 2008.

32. GELATLY R., BECK A. T. Catastrophic Thinking: A Transdiagnostic Process Across Psychiatric Disorders. Cogn Ther Res, v. 40, n. 4, p. 441-452, 2016.

33. GWILYM S. E et al. Psychophysical and functional imaging evidence supporting the presence of central sensitization in a cohort of osteoarthritis patients. Arthritis Rheum v. 61, p. 1226-1234. 2009.

34. HAMANN S. Mapping discrete and dimensional emotions onto the brain: controversies and consensus. Trends Cogn Sci v.16, p.458-66. 2012.

35. HARVIE D. S., EDMOND-HANK G. SMITH A. D. Tactile acuity is reduced in people with chronic neck pain. Musculoskeletal Science and Practice v. 33, p. 61-66. 2018. 
36. HASHMI J. A. Shape shifting pain: chronification of back pain shifts brain representation from nociceptive to emotional circuits. Brain v. 136, p. 2751-2768. 2013. 37. HEERKENS R. J. et al. Motor imagery performance and tactile acuity in patients with complaints of arms, neck and shoulder. Pain management v. $8, \mathrm{n}$. 4, 2018.

38. JUOTTONEN K. et al. Altered central sensorimotor processing in patients with complex regional pain syndrome. Pain v. 98, p. 315-323. 2002.

39. KIBLER W. B. Pain catastrophizing behaviors and their relation to poor patientreported outcomes after scapular muscle reattachment. J Shoulder Elbow Surg, v. 27, n. 9, p. 1564-1571, 2018.

40. KIM J. H. et al. Regional grey matter changes in patients with migraine: a voxelbased morphometry study. Cephalalgia v. 28, p. 598-604. 2008.

41. KOBER H. Functional grouping and cortical-subcortical interactions in emotion: a meta-analysis of neuroimaging studies. NeuroImage v.42, p. 998-1031. 2008.

42. KONG J. et al. S1 is associated with chronic low back pain: a functional and structural MRI study. Molecular Pain. v. 9, n. 3, 2013.

43. KUCHINAD A, et al. Accelerated brain gray matter loss in fibromyalgia patients: premature aging of the brain? J Neurosci v. 27, p. 4004-4007. 2007.

44. KUIJPERS T., et al. Costs of shoulder pain in primary care consulters: a prospective cohort study in The Netherlands. BMC Musculoskelet Disord., v. 7, n. 1, p. 83. 2006.

45. KOO J. P. et al. Two-point discrimination of the upper extremities of healthy Koreans in their 20's. J. Phys. Ther. Sci. v. 28, p. 870-874, 2016.

46. LEWIS J. S. SCHWEINHARDT P. Perceptions of the painful body: The relationship between body perception disturbance, pain and tactile discrimination in complex regional pain syndrome. Eur J Pain, v.16, p. 1320-1330, 2012.

47. LINDQUIST K. A. The brain basis of emotion: a meta-analytic review. Behav Brain Sci v. 35, p. 121-43. 2012.

48. LITTLEWOOD C. et al. The central nervous system e an additional consideration in 'rotator cuff tendinopathy' and a potential basis for understanding response to loaded therapeutic exercise. Man Ther, v. 18, p. 468-72, 2013.

49. LOTZE M. MOSELEY G. L. Role of Distorted Body Image in Pain. Current Rheumatology Reports, v. 9, p. 488-496, 2007.

50. LUEDTKE $\mathrm{K}$. et al. Upper cervical two-point discrimination thresholds in migraine patients and headache-free controls. v. 26, n. 19. 2018.

51. LUMLEY M. A., et al. Pain and Emotion: A Biopsychosocial Review of Recent Research. Journal of Clinical Psychology, v. 67, n. 9, p. 942-968, 2011.

52. LUNDBORG G. ROSEN B. The two-point discrimination test - time for a reappraisal? Journal of Hand Surgery v.29, n. 5, p. 418-422, 2004.

53. MARCUZZI A. et al. The long-term reliability of static and dynamic quantitative sensory testing in healthy individuals. PAIN. v.158, p.1217-1223. 2017.

54. MARTINS J. et al. Versão brasileira do Shoulder Pain and Disability Index: tradução, adaptação cultural e confiabilidade. Rev Bras Fisioter, São Carlos, v. 14, n. 6, p. 527-36, 2010.

55. MARTINEZ-CALDERON J. Influence of psychological factors on the prognosis of chronic shoulder pain: protocol for a prospective cohort study. BMJ Open. v. 6, n.7, p. 3. 2017.

56. MARSHALL P. J., MELTZOFF A. N. Body maps in the infant brain. Trends Cogn Sci. v. 19, p.499-505. 2015 
57. MEULDERS A. et al. Generalization of Pain-Related Fear Using a Left-Right Hand Judgment Conditioning Task. Behavior Therapy, v. 46, p. 699-716, 2015.

58. MILES H., MACLEOD A. K., POTE H. Retrospective and prospective cognitions in adolescents: anxiety, depression, and positive and negative affect. Journal of Adolescence, v. 27, p. 691-701, 2004.

59. MOBERG E. Two point discrimination test. Scand J Rehab Med v. 22, p. 127,134. 1990.

60. MOORE E. et al. Catastrophizing and pain-related fear predict failure to maintain treatment gains following participation in a pain rehabilitation program. Pain Reports, v. 1, n. 2, p. e567, 2016.

61. MOSELEY G. L. Why do people with complex regional pain syndrome take longer to recognize their affected hand? Neurology v. 62, n. 12, p. 2182-2186. 2004.

62. MOSELEY G. L. I can't find it! Distorted body image and tactile dysfunction in patients with chronic back pain. Pain v. 40, p. 239-243. 2008

63. MOSELEY G. L. FLOR H. Targeting cortical representations in the treatment of chronic pain: a review. Neurorehabil Neural Repair, v. 26, p. 646-52, 2012.

64. MOSELEY G. L. et al. The Graded Motor Imagery Handbook. 2012.

65. MOSELEY G. L., GALLAGHER L., GALLACE A. Neglect-like tactile dysfunction in chronic back pain. Neurology, v. 2479, n. 4, p.327-32, 2012.

66. NIJS J. et al. In the Spine or in the brain? Recent advances in pain neuroscience applied in the intervention for low back pain. Clin Exp Rheumatol. v. 107, n. 5, p.108115. 2017.

67. NGOMO S. et al. Alterations in central motor representation increase over time in individuals with rotator cuff tendinopathy. Clin. Neurophysiol. v.126, n. 2, p. 365-71. 2015.

68. NOTEN S. Central Pain Processing in Patients with Shoulder Pain: A Review of the Literature. V. 17, n. 2, p. 267-280. 2017.

69. PARSONS L. M. Integrating cognitive psychology, neurology and neuroimaging. Acta Psychol. v. 107, n. 1-3, p.155-181. 2001.

70. PELDIELD W. BOLDREY E. Somatic motor and sensory representation in the cerebral cortex of man as studied by electrical stimulation. Brain v. 60, n. 4, p. 389- 443. 71. PHILLIPS M. L. et al. The effect of negative emotional context on neural and behavioural responses to oesophageal stimulation. Brain v. 126, p. 669-84. 2003.

72. PIRES P. et al. Positive and Negative Affect Schedule: Psychometric Properties for the Brazilian Portuguese Version. Spanish Journal of Psychology, v. 16, n. 58, p. $1-9,2013$.

73. PLEGER B. et al. Shifts in cortical representations predict human discrimination improvement. PNAS, v. 98, n. 21, p. 12255-12260, 2001.

74. PLEGER B. et al. Patterns of cortical reorganization parallel impaired tactile discrimination and pain intensity in complex regional pain syndrome. NeuroImage. $\mathrm{V}$. 32, p. $503-510.2006$.

75. PUNT T. D. Re: The development of a shoulder specific left/right judgement task: Validity \& reliability. Musculoskeletal Science and Practice, v. 30, p. e87, 2017. 76. REINERSMANN A. et al. Impaired spatial body representation in complex regional pain syndrome type 1 (CRPS I). Pain, v.153, p. 2174-2181, 2012. 
77. REIS F. J. J. et al. Association between pain drawing and psychological factors in musculoskeletal chronic pain: A systematic review. Physiotherapy theory and practice, v. 35, n. 6, p. 533-542, 2019.

78. ROH Y. H. et al. Effect of depressive symptoms on perceived disability in patients with chronic shoulder pain. Arch Orthop Trauma Surg v. 132, p.1251-1257, 2012.

79. ROY J. S. et al. Beyond the joint: The Role of Central Nervous System Reorganization in Chronic musculoskleteal disorders. J Orthop Sports Phys. v.47, n. 11, p. 817-821. 2017.

80. RUMIATI R. I. et al. Neuropsychological perspectives on the mechanisms of imitation. Phil. Trans. R. Soc. B v. 364, p. 2337-2347, 2009.

81. STANTON T. et al. Tactile acuity is disrupted in osteoarthritis but is unrelated to disruptions in motor imagery performance. Rheumatology, v. 52, p.1509-1519, 2013.

82. SEHN F. Cross-Cultural Adaptation and Validation of the Brazilian Portuguese Version of the Pain Catastrophizing Scale. Pain Medicine v. 13, p.1425-1435, 2012.

83. SEITZ A. L. et al. Mechanisms of rotator cuff tendinopathy: intrinsic, extrinsic, or both? Clin Biomech, v. 26, n. 1, p. 1-12, 2011.

84. SCHMID A. B. COPPIETERS M. W. Left/right judgment of body parts is selectively impaired in patients with unilateral carpal tunnel syndrome. Clin. J. Pain v. 8, n. 7, p. 615-622. 2012.

85. SCHMIDT-WILCKE $\mathrm{T}$ et al. Gray matter decrease in patients with chronic tension type headache. Neurology v. 65, p. 1483-1486. 2005.

86. SCHMIDT-WILCKE T. et al. Affective components and intensity of pain correlate with structural differences in gray matter in chronic back pain patients. Pain v. 125, p. 89-97. 2006.

87. SCHMIDT-WILCKE T. Variations in brain volume and regional morphology associated with chronic pain. Curr Rheumatol Rep v.10, p. 467-474. 2008.

88. SCHWOEBEL J. et al. Pain and the body schema: evidence for peripheral effects on mental representations of movement. Brain v. 124, p. 2098-2104. 2001.

89. SHIMOKATA H., KUZUYA F. Two point discrimination test of the skin as an index of sensory aging. Gerontoly, v. 41, p. 267-272, 1995.

90. STANTON T. R. et al. Tactile acuity is disrupted in osteoarthritis but is unrelated to disruptions in motor imagery performance. Rheumatology . v. 52, p. 15091519. 2013.

91. THORPE A. M. Are Psychologic Factors Associated With Shoulder Scores

After Rotator Cuff Surgery? Clin Orthop Relat Res, v. 476, p. 2062-2073, 2018.

92. TREEDE R. D. The International Association for the Study of Pain definition of pain: as valid in 2018 as in 1979, but in need of regularly updated footnotes. Pain

Reports, v. 3, n. 2, p. e643, 2018.

93. TSAO H., GALEA M. P. HODGES P. W. Reorganization of the motor cortex is associated with postural control deficits in recurrent low back pain. Brain v. 131, p. 21612171. 2008.

94. VAN NES S. I. V. et al. Revising two-point discrimination assessment in normal aging and in patients with polyneuropathies. J Neurol Neurosurg Psychiatry v. 79, p. 832-834, 2008.

95. VALFRE W. et al. Voxel-based morphometry reveals gray matter abnormalities in migraine. Headache v. 48, p.109-117. 2008.

VILLEMURE C., BUSHNELL M. C. Cognitive modulation of pain: how do attention and emotion influence pain processing? Pain v. 95, p. 195-9. 2002. 
96. WALLWORK S. B. et al. Neural representations and the cortical body matrix: implications for sports medicine and future directions. Br J Sports Med, p. 1-8, 2015. 97. WEIR J. P. Quantifying test-retest reliability using the intraclass correlation coefficient and the SEM. Journal of Strength and Conditioning Research, v.19, n.1, p. 231-240. 2005.

98. ZANON C. et al. Desenvolvimento e validação de uma escala de afetos positivos e negativos. Psico-USF, v. 18, n. 2, p. 193-202, 2013. 


\section{APÊNDICE A - FICHA DE AVALIAÇÃo}

Ambulatório de Reabilitação do Complexo do Ombro - ARCO

Responsável pela avaliação:

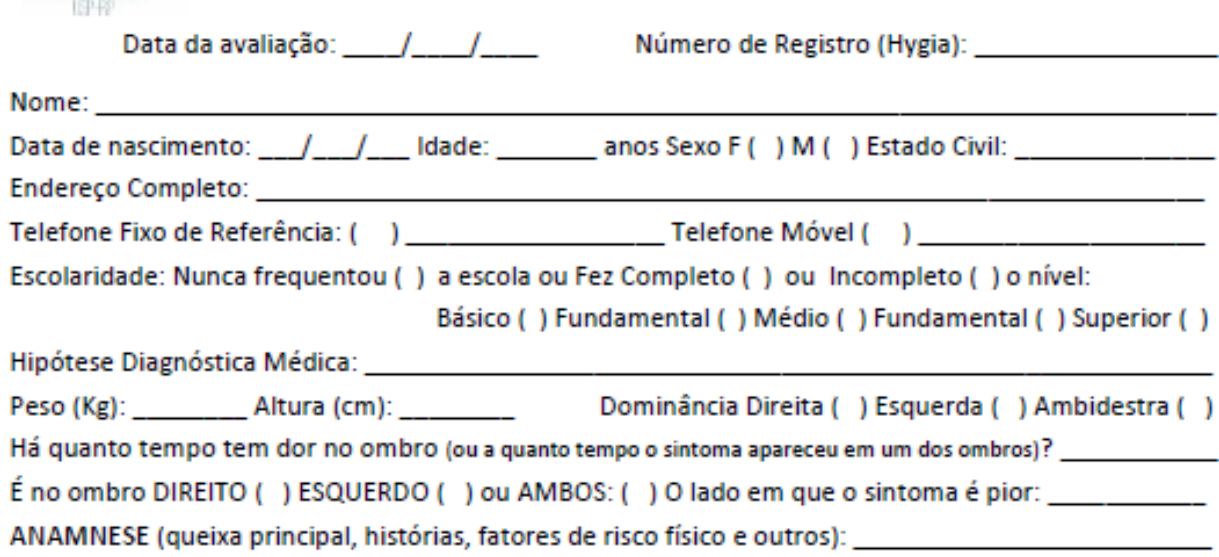

Qual sua expectativa de melhora fazendo fisioterapia?

No último ano, quantas vezes procurou por médicos/outros por causa do seu ombro:

Cirurgia previa no membro superior ou coluna? NÃO ( ) SIM ( ):

Alguma fratura no membro superior, pescoço ou tronco? NÃO ( ) SIM ( ):

Alguma luxação no ombro, cotovelo ou mão? NÃO ( ) SIM ( )

Dor irradiada pelo membro superior ou mãos? NÃO( ) SIM ( ):

Tem doença sistêmica como diabetes, hipertensão, AR*? NÃO( ) SIM ( )

Medicação para dor (Qual?/Dose?):

Exames complementares

Está afastado do seu trabalho por causa da dor no ombro? NÃO ( ) **SIM ( ) meses Ocupação: Envolve alta demanda física ou psicológica NÃO( ) SIM ( )

Sedentário ( ) ou Realiza atividade esportiva/prática corporal. Qual?

Tempo de prática: (anos/meses) Frequência semanal de treino:

Treinamento de musculação ou outro? SIM ( ) NÃO ( ) Frequência Semanal: 
Você está com dor no ombro neste momento? NÃO（） SIM（）

Se SIM, qual é a intensidade da dor que está sentindo no ombro, agora, com o braço parado, em repouso, ao lado do corpo?

END - Assinalar a intensidade da dor usando um número inteiro, informar que $0=\operatorname{sem}$ dor; $10=$ pior dor

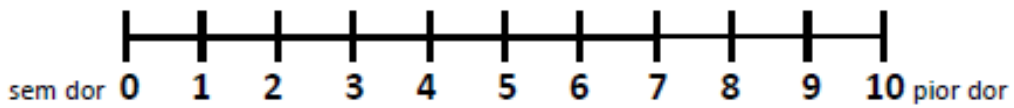

Você sente dor no ombro quando o braço está parado, em repouso? NÃo（） SIM（） NÃO SEl（）

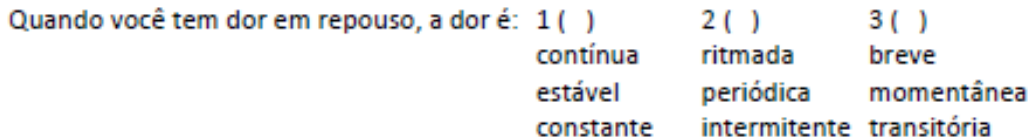

Você sente dor no ombro a noite? NÃO（） SIM（）NÃO SEI（）

$\begin{array}{llll}\text { Quando você tem dor a noite, a dor é: } & 1() & 2() & 3(\text { ) } \\ & \text { contínua } & \text { ritmada breve } \\ \text { estável } & \text { periódica momentânea } \\ & \text { constante } & \text { intermitente transitória }\end{array}$

Preencha no esquema de corpos qual(is) é(são) a(s) região(ões) que melhor representa(m) sua dor

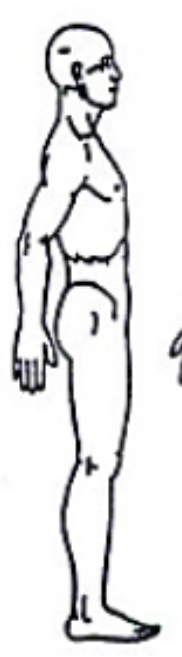

Lado Direito

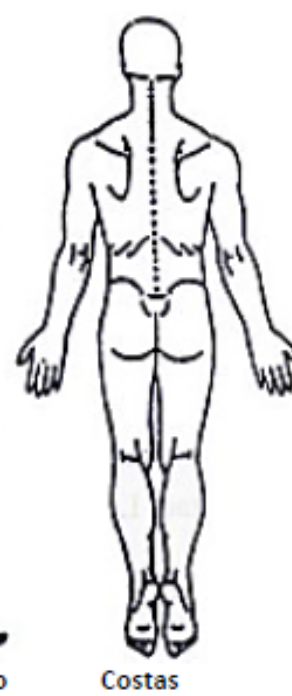

Costas

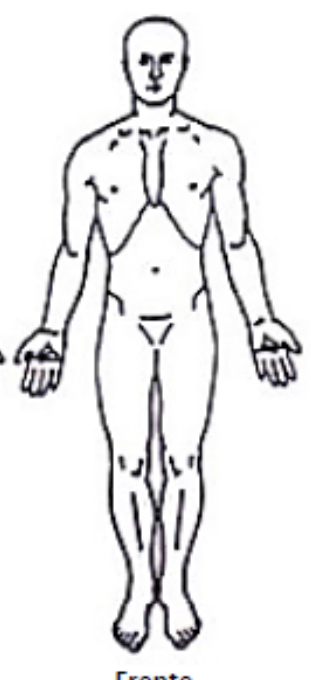

Frente

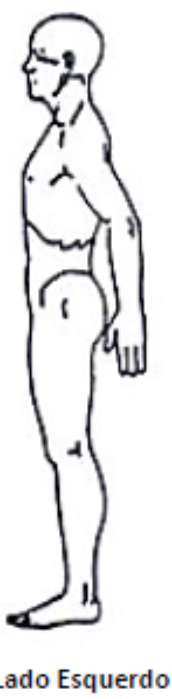




\section{APÊNDICE B - TERMO DE CONSENTIMENTO LIVRE E ESCLARECIDO}

O (a) Sr.(a) está sendo convidado a participar do estudo "Análise da sensibilidade discriminativa de dois pontos e tempo de resposta em tarefa de julgamento de lateralidade em indivíduos com dor no ombro - estudo transversal" que será realizado na cidade de Ribeirão Preto - SP, tendo como responsáveis a Profa. Dra. Anamaria Siriani de Oliveira e a mestranda Marília Caseiro da Faculdade de Medicina de Ribeirão Preto USP e como co-orientador Prof ${ }^{\circ}$ Dr. Felipe Jose Jandre dos Reis, docente do Instituto Federal do rio de Janeiro.

Esclarecimento geral e objetivo do estudo: O objetivo deste estudo será avaliar a sensibilidade discriminativa de dois pontos e o julgamento de lateralidade para o ombro e para outra parte remota do corpo e a predominância de afetos e pensamentos catastróficos em indivíduos com dor crônica no ombro. Sabe-se que investigar mecanismos centrais da dor, pode auxiliar no tratamento e prognóstico das condições dolorosas no ombro. Acredita-se que os pacientes apresentarão alterações na sensibilidade discriminativa e no tempo de resposta e acurácia no julgamento de lateralidade podendo se relacionar com predomínio de afetos negativos e pensamentos catastróficos.

Explicação do procedimento: Se o Sr.(a) aceitar participar da pesquisa Sr.(a) irá responder um questionários que ira avaliar se o Sr.(a) tem dor e incapacidade do ombro (questionário Índice de dor e incapacidade do ombro) e se o Sr.(a) tem predomínio de afetos positivos ou negativos e pensamentos catastróficos, além de uma ficha de avaliação que terá questões de dados pessoais e relacionados a dor no ombro. O Sr.(a) deverá assinalar a área de dor correspondente em um aplicativo que será apresentado através de um Tablet.

Após o Sr.(a) irá participar de um teste, onde será aplicado um instrumento no seu ombro com duas pontas que não oferecem risco de lesão, e será questionado sobre a sensação. Este instrumento também será aplicado no seu outro ombro. Após, será realizado outro teste, onde o Sr.(a), visualizará várias imagens do ombro e do pé e responderá se corresponde à direita ou à esquerda.

Possíveis benefícios: A sua participação no estudo tem como possível benefício permitir que novas descobertas para pacientes com dor no ombro sejam investigadas e que podem ser usadas para melhorias no tratamento dos pacientes. O Sr.(a) terá garantia de acesso ao tratamento.

Desconforto e risco: A pesquisa poderá apresentar risco mínimo a sua saúde. O Sr.(a) poderá sentir um pouco de dor e desconforto após a avaliação e que esses sintomas desaparecerão aos poucos. De qualquer forma os pesquisadores estarão dispostos a solucionar problemas durante e após a realização da pesquisa. Os riscos destes procedimentos serão mínimos por envolver somente medições não invasivas.

Liberdade de participação: A sua participação neste estudo é voluntária. É seu direito interromper sua participação a qualquer momento, sem que isso cause qualquer penalidade ou prejuízo à sua pessoa, comprometendo-se somente a comunicar pelo menos um dos responsáveis da pesquisa. 
Sigilo de identidade: Sua identidade será mantida em sigilo absoluto, as informações obtidas nesta pesquisa serão de maneira alguma associadas a sua identidade e não poderão ser consultadas por pessoas leigas sem sua autorização oficial. Estas informações poderão ser utilizadas para fins estatísticos ou científicos, desde que fiquem guardados a sua identidade e seu anonimato.

Ressarcimento de despesa e indenização: Pela sua participação, o Sr.(a) não receberá nenhum tipo de seguro de vida ou saúde que possa beneficiá-lo. Caso sinta-se prejudicado(a) ou lesado(a) por participar da pesquisa, o Sr.(a) deverá buscar indenização nas Leis vigentes no Brasil. Os responsáveis pelo estudo explicarão todos os riscos envolvidos, a necessidade da pesquisa e se prontificarão a responder todas as suas dúvidas.

O Sr.(a) recebera uma via deste documento assinado pelo participante e pelo pesquisador responsável. Se o Sr.(a) quiser saber quais são os resultados da sua avaliação o pesquisador responsável irá lhe entregar um relatório com os resultados.

$\mathrm{Eu}$,

Residente à portador do $\mathrm{RG} \mathrm{n}^{\circ}$

Cidade bairro

em participar, voluntariamente, na pesquisa conduzida pelos alunos responsáveis e por seu (sua) respectivo(a) orientador(a).

Nome Participante: Data:

Assinatura Participante:

Nome Pesquisador: , Data:

Assinatura Pesquisador:

Para questões relacionadas a este estudo, contate:

Comitê de Ética do Centro Saúde Escola - CSE 1633150000

Profa. Dra. Anamaria Siriani de Oliveira, Curso de Fisioterapia - Faculdade de Medicina de Ribeirão Preto - FMRP-USP: (16) 3315-4413 - siriani @ fmrp.usp.br Mestranda: Marília Caseiro, Pós graduação em Reabilitação e desempenho funcional - Faculdade de Medicina de Ribeirão Preto - FMRP-USP: (16) 3315-0737 -mariliacaseiro@usp.br 


\section{ANEXO A - PARECER COMITÊ DE ÉTICA}

\section{CENTRO DE SAÚDE ESCOLA}

FACULDADE DE MEDICINA DE RIBEIRĀO PRETO

UNIVERSIDADE DE SÃO PAULO

OF. 013/2017-CEP/CSE-FMRP-USP

Ribeirz̃o Preto, 14 de Junho de 2017.

Prezada Senhora

Comunicamos que o projeto de pesquisa abaixo especificado foi analisado e APROVADO ad referendum do Comitê de Ética em pesquisa do Centro de Saúde Escola da Faculdade de Medicina de Ribeirão Preto da Universidade de São Paulo, na data de 13 de Junho de 2017.

CAAE:65423616.3.0000.5414

Projeto de pesquisa: "Análise da sensibilidade discriminativa de dois pontos e tempo de resposta em tarefa de julgamento de lateralidade em indivíduos com dor no ombro - estudo transversal"

Pesquisador: Marilia Caseiro

Em atendimento à Resoluçăo $466 / 12$, deverá ser encaminhado a este CEP o relatório final da pesquisa e a publicaçăo de seus resultados, para acompanhamento, bem como comunicada qualquer intercorrência ou a sua interrupção.

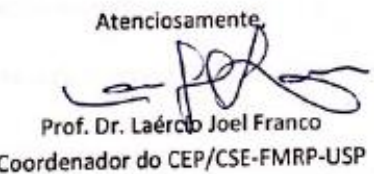

Ilma. Profa. Dra. Anamaria Siriani de Oliveira

Docente do Departamento de Biomecânica, Medicina e Reabilitaçăo do Aparelho Locomotor da Faculdade de Medicina de Ribeirão Preto-USP 


\section{USP - CENTRO DE SAÚDE \\ ESCOLA DA FACULDADE DE MEDICINA DE RIBEIRĀO}

Platoformo

\section{PARECER CONSUBSTANCIADO DO CEP}

DADOS DO PROJETO DE PESQUISA

Tutule das Pesquisa: Andise da seosithidade discriminativa de dois pontos e tempo de resposta em tarefa te fulgamento de lateralidade em individuas com dor no ombro $<$ ast

Pesqquisador: Martia Caseiro

Area Tematica:

Versao: 3

CAAE: 65423616.30000 .5414

Instituiçào Proponente: Centro de Saúde Escola - Faculdade de Medicina de Ribeirăo Preto - USP

Patrocinador Princlpal: Financiamento Próprio

\section{DADOS DO PARECER}

Nùmero do Parecer: 2.117.438

Apresentaçào do Projeto:

Resposta a parecer que solicita correçâo do endereço do CEP que analisa o projeto.

A correçáo foi realizada apenas no TCLE, permanecendo a incorreçăo no projeto detalhado.

Objetivo da Pesquisa:

Avaliar a sensibilidade discriminativa de dois pontos e a capacidade de julgamento de lateralidade em pessoas com dor crônica em ombro.

Avallaçào dos Rlscos e Beneficlos:

Vide parecer anterior.

Comentarlos e Consideraçঠes sobre a Pesquisa:

Vide parecer anterior.

Conslderaçóces sobre os Termos de apresentaçăo obrigatória:

Adequados.

Recomendaçōes:

Corrigir o nome e endereço do CEP que analisou o processo na brochura do projeto (projeto detalhado)

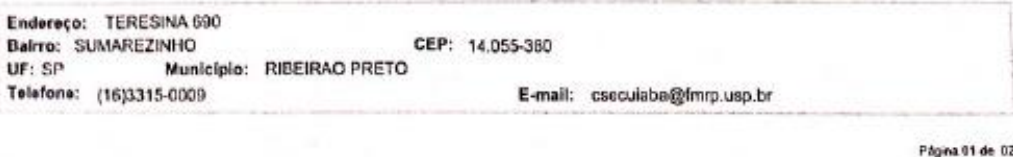


Contnuaşa do Parecer: 2.117 .438

Conclusōes ou Pendências e Lista de Inadequaçōes:

Recomendo aprovar o projeto.

Consideraçōes Finais a critério do CEP:

Aprovar o projeto "ad referendum".

Este parecer foi elaborado baseado nos documentos abaixo relacionados:

\begin{tabular}{|c|c|c|c|c|}
\hline Tipo Documento & Arquivo & Postagem & Autor & Situaçăo \\
\hline $\begin{array}{l}\text { Informaçōes Básicas } \\
\text { do Projeto }\end{array}$ & $\begin{array}{l}\text { PB_INFORMAČOCES_BASICAS_DO_P } \\
\text { ROJETO 814556.pdf }\end{array}$ & $\begin{array}{c}12 / 06 / 2017 \\
13: 55: 46\end{array}$ & & Aceito \\
\hline $\begin{array}{l}\text { Projeto Detalhado / } \\
\text { Brochura } \\
\text { Investigador }\end{array}$ & projeto_mestrado.docx & $\begin{array}{l}12 / 06 / 2017 \\
11: 33: 54\end{array}$ & Marília Caseiro & Aceito \\
\hline $\begin{array}{l}\text { TCLE / Termos de } \\
\text { Assentimento / } \\
\text { Justificativa de } \\
\text { Ausência } \\
\end{array}$ & TCLE.doc $x$ & $\begin{array}{c}12 / 06 / 2017 \\
11: 33: 33\end{array}$ & Marilia Caseiro & Aceito \\
\hline $\begin{array}{l}\text { Declaraçăo de } \\
\text { Instituiçắo e } \\
\text { Infraestrutura }\end{array}$ & Clinica_Barao.pdf & $\begin{array}{l}06 / 03 / 2017 \\
21: 11: 24\end{array}$ & Marilia Caseiro & Aceito \\
\hline $\begin{array}{l}\text { Declaração de } \\
\text { Instituição e } \\
\text { Infraestrutura } \\
\end{array}$ & Clinica_Particular.jpeg & $\begin{array}{l}06 / 03 / 2017 \\
21: 10: 33\end{array}$ & Marilia Caseiro & Aceito \\
\hline $\begin{array}{l}\text { Dectaraçāo de } \\
\text { Instituiçăo e } \\
\text { Infraestrulura }\end{array}$ & Secretaria_Municipal.jpeg & $\begin{array}{c}06 / 03 / 2017 \\
21: 09: 02\end{array}$ & Marilia Caseiro & Aceito \\
\hline Folha de Rosto & folha_rosto.pdf & $\begin{array}{c}18 / 12 / 2016 \\
20: 54: 48\end{array}$ & Marília Caseiro & Aceito \\
\hline
\end{tabular}

Situação do Parecer:

Aprovado

Necessita Apreciaçăo da CONEP:

Nāo

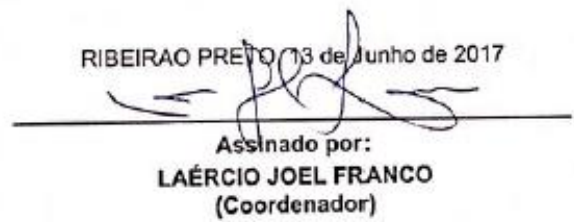

(Coordenador)

Endereço: TERESINA 690

Bairro: SUMAREZINHO

UF: SP Municipio: RIBEIRAO PRETO

Telefone: (16)3315-0009

CEP: $14.055-380$

E-mail: esceudaba@imrp.usp.b

Paynas 02 đe 02 
OF. $4816 / 2016$

DBSJ/dbsj

Ribeirão Preto, 06 de dezembro de 2016.

Senhora Orientadora,

Informo que os responsáveis das unidades CSE Sumarezinho (CSE Cuiabá) e do serviço de fisioterapia do Centro Universitário Barão de Mauá manifestaram a concordância de que a coleta de dados do projeto de pesquisa seja realizada nas referidas unidades conveniadas com a Secretaria da Saúde de Ribeirão Preto desde que não atrapalhe a rotina de atendimento.

Sendo assim, declaro estar ciente e concordo com a realização do projeto de pesquisa "Análise da sensibilidade discriminativa de dois pontos e tempo de resposta em tarefa de julgamento de lateralidade em indivíduos com dor no ombro - estudo transversal", sob a responsabilidade da pesquisadora ANAMARIA SIRIANI DE OLIVEIRA (Faculdade de Medicina de Ribeirão Preto da Universidade de São Paulo).

Informo que a pesquisa somente poderá iniciar quando obtiver a aprovação do Comitê de Ética em Pesquisa da instituição proponente.

Solicito que a pesquisadora encaminhe à Secretaria Municipal da Saúde o Relatório Final ao encerrar a pesquisa.

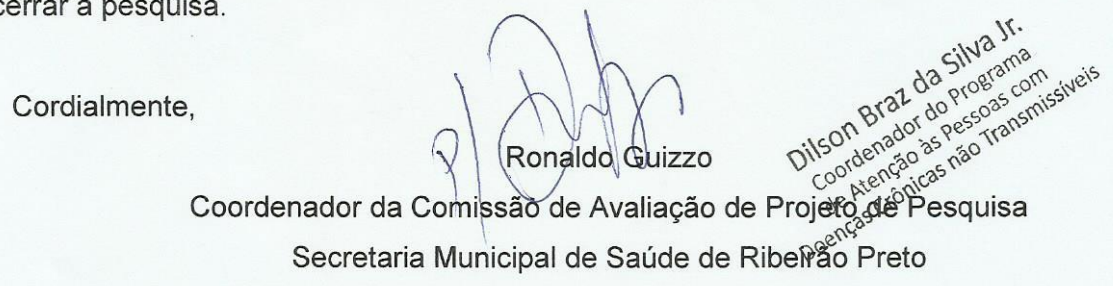

Ilustríssima Senhora

ANAMARIA SIRIANI DE OLIVEIRA

FACULDADE DE MEDICINA DE RIBEIRÃO PRETO - USP

Secretaria Municipal da Saúde

Rua Prudente de Moraes, 457 - Centro - Ribeirão Preto/SP

Fones: 3977.9305 / Fax: 3941.4934 / e-mail: gabinete@saude.pmrp.com.br 
ANEXO C - POSITIVE AND NEGATIVE AFFECTIVE SCALE - PANAS

ESCALA DE AFETO NEGATIVO E POSITIVO - PANAS

\section{Instruções}

Este questionário é composto por palavras ou frases que descrevem diferentes modos de sentir ou de pensar sobre si mesmo. Leia cada item e, em seguida, assinale o número que vem ao lado direito da palavra que melhor caracteriza o seu modo de ser (determine aqui o espectro temporal que pretende av aliar). Não há respostas certas ou erradas.

\begin{tabular}{|c|c|c|c|c|c|c|}
\hline & Item & Muito pouco/nada & Um pouco & Médio & Muito & Bastante/sempre \\
\hline 01 & Ativo & 1 & 2 & 3 & 4 & 5 \\
\hline 02 & Alerta & 1 & 2 & 3 & 4 & 5 \\
\hline 03 & Atento & 1 & 2 & 3 & 4 & 5 \\
\hline 04 & Com orgulho de si & 1 & 2 & 3 & 4 & 5 \\
\hline 05 & Determinado & 1 & 2 & 3 & 4 & 5 \\
\hline 06 & Entusiasmado & 1 & 2 & 3 & 4 & 5 \\
\hline 07 & Empolgado & 1 & 2 & 3 & 4 & 5 \\
\hline 08 & Inspirado & 1 & 2 & 3 & 4 & 5 \\
\hline 09 & Interessado & 1 & 2 & 3 & 4 & 5 \\
\hline 10 & Forte & 1 & 2 & 3 & 4 & 5 \\
\hline 11 & Com medo & 1 & 2 & 3 & 4 & 5 \\
\hline 12 & Envergonhado & 1 & 2 & 3 & 4 & 5 \\
\hline 13 & Aflito & 1 & 2 & 3 & 4 & 5 \\
\hline 14 & Culpado & 1 & 2 & 3 & 4 & 5 \\
\hline 15 & Hostil & 1 & 2 & 3 & 4 & 5 \\
\hline 16 & Irritável & 1 & 2 & 3 & 4 & 5 \\
\hline 17 & Inquieto & 1 & 3 & 3 & 4 & 5 \\
\hline 18 & Nervoso & 1 & 2 & 3 & 4 & 5 \\
\hline 19 & Apavorado & 1 & 2 & 3 & 5 \\
\hline 20 & Chateado & 1 & 2 & 2 & 4 & 5 \\
\hline
\end{tabular}


ANEXO D - ESCALA DE PENSAMENTOS CATASTRÓFICOS - PCS

Escala de Pensamento Catastrófico sobre a Dor (B-PCS)

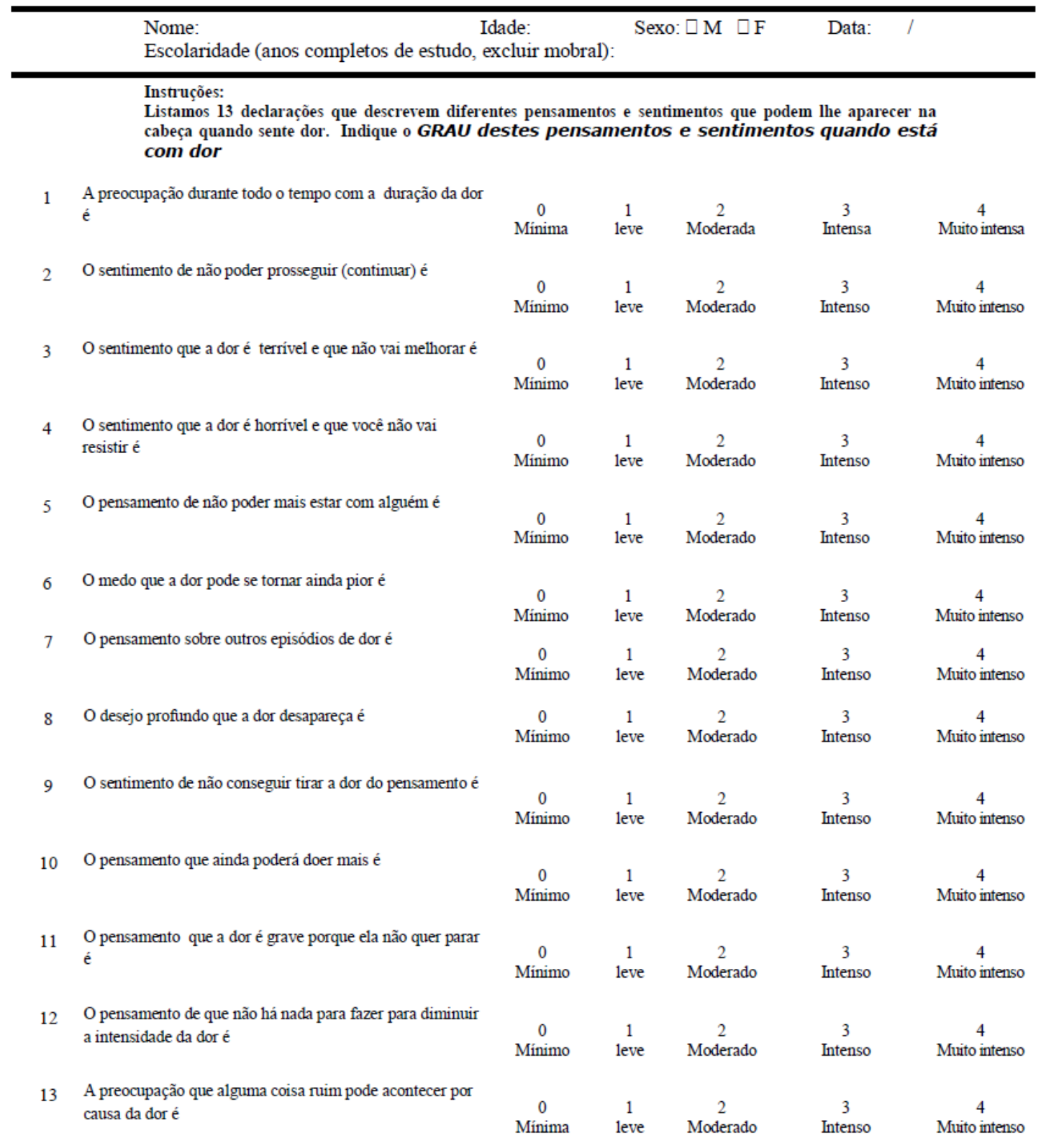

